\title{
Contribution of Different Time-Scale Variations to the Tropical Cyclogenesis Environment over the Northern Tropical Atlantic and Comparison with the Western North Pacific
}

\author{
Xi CaO, ${ }^{\mathrm{a}, \mathrm{b}}$ Renguang Wu, ${ }^{\mathrm{a}, \mathrm{c}}$ Mingyu Bi, ${ }^{\mathrm{d}}$ Xiaoqing Lan, ${ }^{\mathrm{a}}$ Yifeng Dai, ${ }^{\mathrm{e}}$ And Junhu ZhaO ${ }^{\mathrm{f}}$ \\ ${ }^{a}$ Center for Monsoon System Research, Institute of Atmospheric Physics, Chinese Academy of Sciences, Beijing, China \\ ${ }^{\mathrm{b}}$ State Key Laboratory of Severe Weather, Chinese Academy of Meteorological Sciences, Beijing, China \\ ${ }^{\mathrm{c}}$ State Key Laboratory of Numerical Modeling for Atmospheric Sciences and Geophysical Fluid Dynamics, Institute of \\ Atmospheric Physics, Chinese Academy of Sciences, Beijing, China \\ ${ }^{\mathrm{d}}$ International Laboratory on Climate and Environment Change and Key Laboratory of Meteorological Disaster, \\ Nanjing University of Information Science and Technology, Nanjing, China \\ ${ }^{\mathrm{e}}$ Tongji Zhejiang College, Jiaxing, Zhejiang, China \\ ${ }^{\mathrm{f}}$ Laboratory for Climate Studies, National Climate Center, China Meteorological Administration, Beijing, China
}

(Manuscript received 27 August 2018, in final form 24 January 2019)

\begin{abstract}
The present study investigates relative contributions of interannual, intraseasonal, and synoptic variations of environmental factors to tropical cyclone (TC) genesis over the northern tropical Atlantic (NTA) during July-October. Analysis shows that convection, lower-level vorticity, and midlevel specific humidity contribute to TC genesis through intraseasonal and synoptic variations with a larger contribution of the latter. The relative contribution of three components of vertical wind shear depends largely on its magnitude. The contribution of sea surface temperature (SST) to TC genesis is mainly due to the interannual component when total SST is above $27.5^{\circ} \mathrm{C}$. The barotropic energy for the development of synoptic-scale disturbances comes mainly from climatological mean flows and intraseasonal wind variations. The proportion of contribution between synoptic and intraseasonal variations of convection, relative vorticity, and specific humidity is larger over the eastern NTA than over the western NTA. The barotropic energy conversion has a larger part related to climatological mean flows and intraseasonal wind variations over the eastern and western NTA, respectively. There are notable differences between the NTA and the western North Pacific (WNP). One is that the relative contribution of synoptic variations of convection, relative vorticity, and specific humidity is larger over the NTA, whereas that of intraseasonal variations is larger over the WNP. The other is that the barotropic energy conversion related to climatological mean flows and intraseasonal wind variations is comparable over the NTA, whereas that related to climatological mean flows is larger over the WNP.
\end{abstract}

\section{Introduction}

Tropical cyclones (TCs) are one of the most devastating weather events over the globe. The yearly number of TCs over the northern Atlantic Ocean ranks the third over the globe following the western North Pacific (WNP) and eastern North Pacific (Gray 1968). The TCs over the northern Atlantic Ocean influence the United States, Mexico, the Atlantic coast, the Gulf Coast, and the Caribbean islands, leading to substantial loss of life and destruction of property (Pielke and Landsea 1998). Thus, it is of prominent importance to understand the

Corresponding author: Prof. Renguang Wu, renguang@mail. iap.ac.cn mechanisms responsible for TC genesis over the northern Atlantic Ocean.

Previous studies mostly diagnosed the conditions of TC genesis on a large spatial scale and over a certain period according to composite of various fields based on the phases of climate modes (e.g., Maloney and Hartmann 2000; Elsner 2003; Camargo et al. 2007, 2009). However, TC genesis is a local and instantaneous weather event, whose condition is determined by a combination of different time-scale variations of environmental factors. Previous studies have demonstrated the effect of convective and synoptic scales in the Atlantic TC geneses (e.g., Shapiro 1977, Thorncroft and Hodges 2001; Dunkerton et al. 2009; McTaggartCowan et al. 2013). Thus, it is necessary to examine the 
instantaneous state around the location of TC genesis to investigate the relative contributions of different time-scale variations of large-scale factors to TC genesis. This local and instantaneous perspective was recently adopted by Cao et al. (2018) in their analysis of conditions of TC genesis over the WNP. In like manner, we apply the same approach to TC genesis over the northern Atlantic Ocean.

TC genesis depends on regional dynamic and thermodynamic factors, including sea surface temperature (SST), conditional instability, midlevel relative humidity, lower-level vorticity, and vertical wind shear (Gray 1968; Camargo et al. 2007). Over the northern Atlantic Ocean, those large-scale environmental conditions are significantly modulated by various climate modes, such as El Niño-Southern Oscillation (ENSO) (Gray 1984; Camargo et al. 2007), the Atlantic multidecadal oscillation (AMO) (Goldenberg et al. 2001), the North Atlantic Oscillation (NAO) (Elsner 2003; Xie et al. 2005), the Atlantic meridional mode (AMM) (Smirnov and Vimont 2011; Patricola et al. 2014), and the Madden-Julian oscillation (MJO) (Maloney and Hartmann 2000; Maloney and Shaman 2008; Klotzbach 2010). These climate modes affect TC genesis through modulation of variations of various factors on different time scales. For example, Camargo et al. (2007) showed that midlevel relative humidity and vertical wind shear are the two important factors for the reduction of TC genesis over the northern Atlantic Ocean during the El Niño years. Camargo et al. (2009) identified that midlevel relative humidity is a primary contributor of the MJO to the modulation of TCs, followed by lower-level relative vorticity, and there are very minor contributions from vertical wind shear and potential intensity. These results indicate that the contribution of various factors to TC genesis may depend upon the time scale.

On the synoptic time scale, the African easterly waves (AEWs) have been found to be a primary precursor for TC genesis over the northern Atlantic Ocean (Burpee 1972; Reed et al. 1977; Thorncroft and Hodges 2001; Chen et al. 2008; Russell et al. 2017). The AEWs are generated over the Sahel through baroclinic and barotropic instability in association with the African easterly jet during the West African monsoon period and propagate westward over the Atlantic Ocean (Burpee 1972; Reed et al. 1977; Chen et al. 2008). Meantime, the AEWs may be generated in the intertropical convergence zone through condensational heating and localized forcing upstream of existing AEWs (Hsieh and Cook 2005; Diaz and Aiyyer 2013). About $80 \%-90 \%$ of hurricanes and about $60 \%$ of all TCs originate from AEWs over the northern Atlantic Ocean (Landsea 1993; Avila and Pasch 1995; Avila et al. 2000; Russell et al. 2017). Russell et al. (2017) quantified the AEW activity by eddy kinetic energy and showed that the correlation between seasonal-mean eddy kinetic energy and TC genesis is maximized at lower levels along the southern track of AEWs. On the other hand, other studies indicated that a substantial portion of TC cyclogenesis is not directly related to AEWs (e.g., McTaggartCowan et al. 2013).

This work attempts to address the environmental conditions for the TC genesis over the northern Atlantic Ocean and make a comparison of these conditions between the northern Atlantic Ocean and the WNP through a new composite method used in Cao et al. (2018). First, we examine the relative contributions to TC genesis of various environmental factors in relation to variations on three time scales (interannual, intraseasonal, and synoptic variations) over the northern Atlantic Ocean. Then, we compare the contributions among three time-scale variations of environmental factors to TC genesis between the western and eastern parts of the northern Atlantic Ocean. Last, we compare the relative contributions of three time-scale variations of large-scale factors to TC genesis between the northern Atlantic Ocean and the WNP.

The rest of the paper is organized as follows. The data and methods are described in section 2. Section 3 examines the percentage contributions of three timescale variations of environmental factors to TC genesis over the northern Atlantic Ocean. Section 4 compares contributions of different time-scale variations of environmental factors to TC genesis between the eastern and western northern Atlantic Ocean and between the northern Atlantic Ocean and the WNP. A summary and discussion are provided in section 5 .

\section{Data and methods}

The TC genesis data over the northern Atlantic Ocean are obtained from the U.S. best track hurricane database (HURDAT1), archived in National Climate Data Center's International Best Track Archive for Climate Stewardship (IBTrACS) v03r10 (Knapp et al. 2010). It includes position of TC center and the maximum sustained wind speed of each TC case every $6 \mathrm{~h}$. The occurrence of TC genesis is defined as the first position of TC best-track data at which the maximum sustained wind speed reaches $25 \mathrm{kt}\left(12.9 \mathrm{~m} \mathrm{~s}^{-1}\right)$ over the northern Atlantic Ocean.

The daily mean interpolated satellite outgoing longwave radiation (OLR) is used as an indicator for deep convection obtained from the National Oceanic 
and Atmosphere Administration (NOAA) (Liebmann and Smith 1996). Conventional dynamic and thermodynamic variables are obtained from the European Centre for Medium-Range Weather Forecasts (ECMWF) interim reanalysis (ERA-Interim) dataset with a horizontal resolution of $0.5^{\circ}$ in latitude and longitude (Dee et al. 2011). We also use the variables from the National Centers for Environmental Prediction (NCEP)-National Center for Atmospheric Research (NCAR) reanalysis dataset with a horizontal resolution of $2.5^{\circ}$ in latitude and longitude (Kalnay et al. 1996). The results from the NCEP-NCAR and ERA-Interim data show that the basic characteristics are mostly the same, although there are some differences in the specific humidity. Only the results from the ERAInterim data are shown in the present study, unless otherwise specified. The daily mean SST is extracted from the NOAA Optimum Interpolation (OI) SST V2 data with a $0.25^{\circ}$ horizontal resolution starting from September 1981 (Reynolds et al. 2007). The original SST data are converted to $1^{\circ}$ horizontal resolution. Because of the limitation of length of SST data, only the period 1982-2013 is analyzed to examine the relative contributions of different time-scale variations of SST to TC genesis.

The interannual ( $>90$ days), intraseasonal (10-90 days), and synoptic (3-8 days) components of variations of various variables are obtained using the same method as in Cao et al. $(2017,2018)$. The interannual component is obtained by applying a 91-day running mean to the original daily anomaly time series. The intraseasonal component is obtained by subtracting a 91-day running mean from a 9-day running mean of the original daily anomaly time series. The synoptic component is obtained by subtracting a 9-day running mean from a 2-day running mean of the original daily anomaly time series. We note that the synoptic and intraseasonal components obtained by the temporal filtering method may already include the modulating effects of the interannual component.

In this study, we use eddy kinetic energy as a measure of synoptic disturbances and investigate the contribution to TC genesis of barotropic energy conversion from climatological mean flows and interannual and intraseasonal wind variations. The equation of the barotropic energy conversion (e.g., Lau and Lau 1992; Maloney and Hartmann 2001) is given by

$$
\frac{\partial K_{\mathrm{baro}}^{\prime}}{\partial t}=-\overline{u^{\prime} v^{\prime}} \frac{\partial \bar{u}}{\partial y}-\overline{u^{\prime} v^{\prime}} \frac{\partial \bar{v}}{\partial x}-\overline{u^{\prime} u^{\prime}} \frac{\partial \bar{u}}{\partial x}-\overline{v^{\prime} v^{\prime}} \frac{\partial \bar{v}}{\partial y},
$$

where $\partial K_{\mathrm{baro}}^{\prime} / \partial t$ is the time rate of change of the eddy kinetic energy through the barotropic energy conversion,
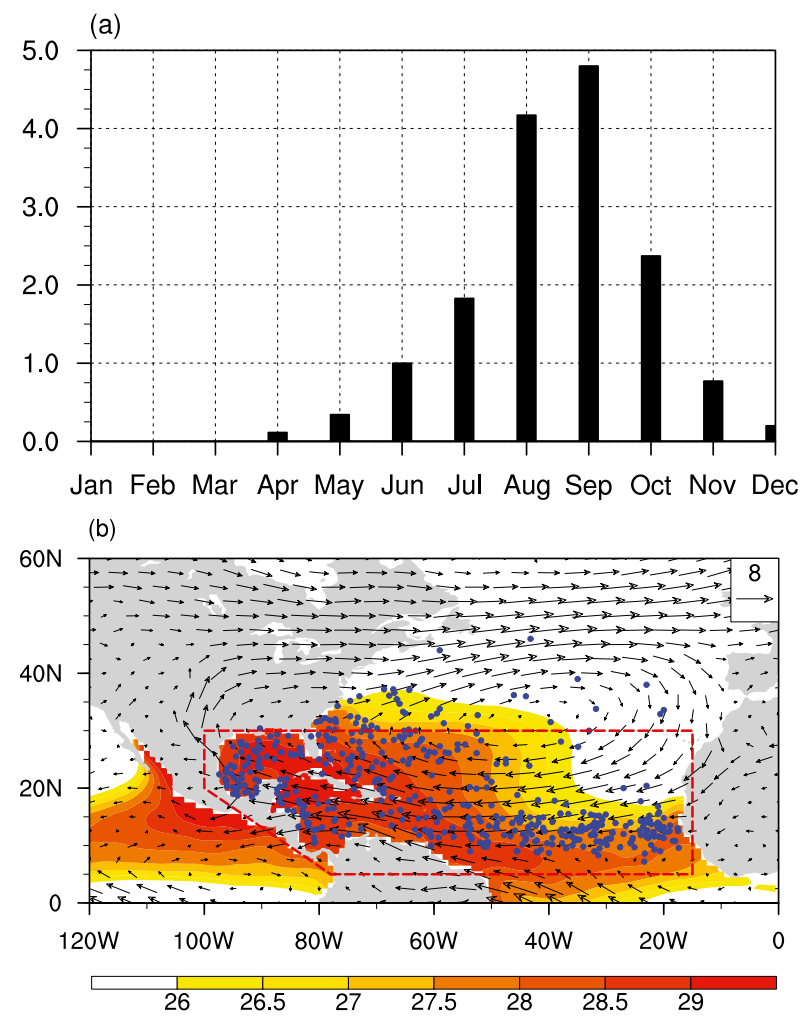

FIG. 1. (a) The climatological monthly variation of the number of TC formation over the NTA averaged for the period 1979-2013. (b) The long-term-mean SST (shaded) and $850-\mathrm{hPa}$ winds (vectors) averaged from July to October for the period 1979-2013. All July-October TC formation locations are shown with blue dots. The red box is the major TC genesis region $\left(5^{\circ}-30^{\circ} \mathrm{N}, 15^{\circ}-100^{\circ} \mathrm{W}\right)$, excluding the east Pacific.

$(\bar{u}, \bar{v})$ are the basic flows, and $\left(u^{\prime}, v^{\prime}\right)$ are the eddy winds on 3-8-day time scale. To investigate the contribution of different time-scale variations of the basic flows, the basic flows are separated into climatological mean winds and interannual and intraseasonal wind anomalies as given by $\bar{u}=u_{\mathrm{cli}}+u_{\text {int }}+u_{\text {iso }}$ and $\bar{v}=v_{\text {cli }}+v_{\text {int }}+v_{\text {iso }}$. As such, each of the four terms in the right-hand side of above equation includes three parts that are in relation to climatological mean winds and interannual and intraseasonal wind variations, respectively.

To determine the active TC season and the main TC genesis region over the northern Atlantic Ocean, we show in Fig. 1a climatological monthly number of TCs forming over the northern Atlantic Ocean for the period 1979-2013. The maximum number of TC formations occurs in September and there is no TC formation during January-March, consistent with previous studies (e.g., Camargo et al. 2007). The most frequent TC genesis occurs from July to October (JASO), which is the same as over the WNP (Cao et al. 2018). Thus, the present analysis focuses on 
the TC genesis in these 4 months. Figure $1 \mathrm{~b}$ displays long-term-mean SST and $850-\mathrm{hPa}$ winds averaged from July to October, overlapped by TC genesis positions for the period $1979-2013$. The area $5^{\circ}-30^{\circ} \mathrm{N}$, $15^{\circ}-100^{\circ} \mathrm{W}$, excluding the eastern Pacific, is selected as the key region representing the majority of $\mathrm{TC}$ genesis during the active TC season over the northern tropical Atlantic (NTA). In this region, climatological mean winds are easterly at the lower level. Meantime, most TCs form in the region with SST above $27.5^{\circ} \mathrm{C}$. The number of TC formations in this region is 414 during JASO for the period 1979-2013, which includes about $90 \%$ of the total number of TCs (461) over the whole northern Atlantic Ocean. For the period 1982-2013, there are 366 TC cases (7 TCs are not included due to missing data) over the NTA during JASO.

The percentage contributions of different time-scale variations of environmental factors are calculated using the same way as in Cao et al. (2018), which is described below. First, we calculate the daily total anomaly of each variable and its decomposition on three time scales averaged in a $7.5^{\circ} \times 7.5^{\circ}$ box centered at the TC genesis location except for SST, which is averaged in a $5^{\circ} \times 5^{\circ}$ box for each TC genesis over the NTA. The values of the total anomaly and the three components vary with the TC. Second, the total anomalies of each variable are divided into 10 nearly equal ranges based on their distributions. Each range may contain individual anomalies corresponding to several TCs. Corresponding to each range, we calculate the averaged total anomaly of each variable as well as the three components by dividing the sum of those anomalies by the number of TCs falling in this specific range. This determines the averaged total anomaly and its three components in each range. Third, the percentage contributions of three time-scale variations of each variable in each range are calculated by dividing the averaged anomaly on one time scale by the absolute value of the averaged total anomaly in each range. Note that the averaged anomalies on different time scales in each range are not necessarily of the same sign. As such, the percentage contribution of individual time scales may be negative. The percentage of TC genesis in each range is calculated by dividing the number of TC genesis in that range by the whole number (414 or 366) of TC genesis.

\section{Contributions of different time-scale variations to TC genesis}

In this section, we analyze contributions of variations of environmental factors on different time scales to TC genesis over the NTA during JASO for the period
1979-2013. As in Cao et al. (2018), six parameters are considered, including OLR, lower-level relative vorticity at $850 \mathrm{hPa}$, midlevel specific humidity at $700 \mathrm{hPa}$, vertical zonal wind shear between 200 and $850 \mathrm{hPa}$, SST, and barotropic energy conversion at $850 \mathrm{hPa}$. As we know, high midlevel humidity is favorable for the development of convection (Gray 1979; Camargo et al. 2007). TC genesis is associated with weak vertical wind shear. The detrimental effect of strong large-scale vertical wind shear on TC development has been well examined (Gray 1979; DeMaria 1996). The large vertical wind shear removes the accumulated condensational heating away from the center of tropical disturbance, inhibiting further decrease of surface pressure and intensification of cumulus convection. Those hold back the further intensification of tropical disturbances into TCs. The warm SST provides the near-surface moisture and upward heat flux to spawn tropical disturbances. Peng et al. (2012) indicated that a warmer SST favors more TC genesis over the NTA through comparing developing and nondeveloping disturbances.

\section{a. OLR, vorticity, and specific humidity}

Figure 2 displays the percentage contributions of OLR, 850-hPa relative vorticity, and 700-hPa specific humidity anomalies due to interannual, intraseasonal, and synoptic components and the percentage of TC genesis frequency represented by the probability density function (PDF). Note that the 10 ranges are divided based on total anomalies and total values in the left and right columns, respectively. For example, in Fig. 2a for OLR, the black line shows the PDF of TC genesis with the scale in percent given on the right $y$ axis and the $x$ axis shows the bins of the OLR. For each range of OLR, we then show the relative contribution of the interannual (red), intraseasonal (green), and synoptic (orange) time scales to that OLR value with the scale in percent given on the left $y$ axis. For example, about $11.4 \%(47 / 414)$ of TCs occur in the range of OLR anomalies between -40 and $-50 \mathrm{~W} \mathrm{~m}^{-2}$ and about $55 \%$ of the OLR anomaly in that range come from the synoptic component. Most TCs $(79 \% ; 328 / 414)$ form when the OLR anomalies are between 0 and $-50 \mathrm{Wm}^{-2}$ (Fig. 2a). The largest positive contribution is from the synoptic variation. The intraseasonal variation plays a secondary role. The contribution from the interannual variation is small. When the OLR anomalies are below $-50 \mathrm{~W} \mathrm{~m}^{-2}$, the contributions from the synoptic and intraseasonal variations are comparable (Fig. 2a). There are 36 TCs (about 9\% of total) when the OLR anomalies are positive and the synoptic variation has the most negative contribution to TC genesis in this range. According to the distribution 

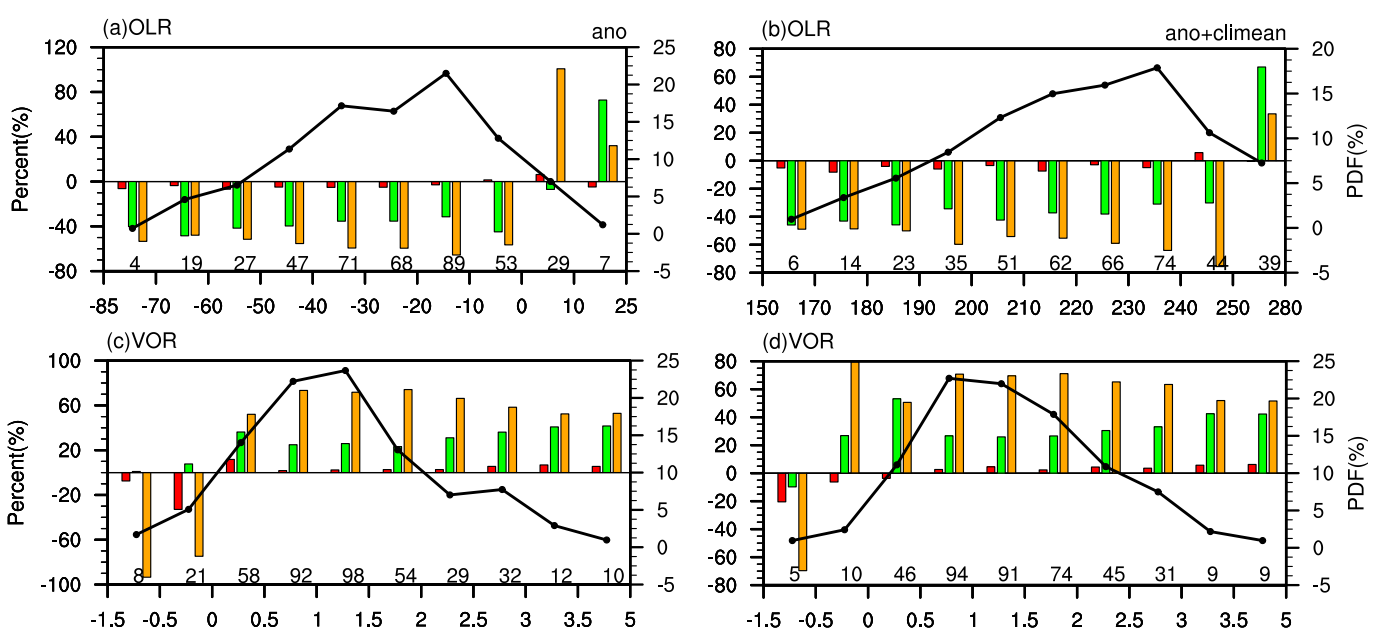

$\begin{array}{lllllllllll}50 & 170 & 180 & 190 & 200 & 210 & 220 & 230 & 240 & 250 & 280\end{array}$
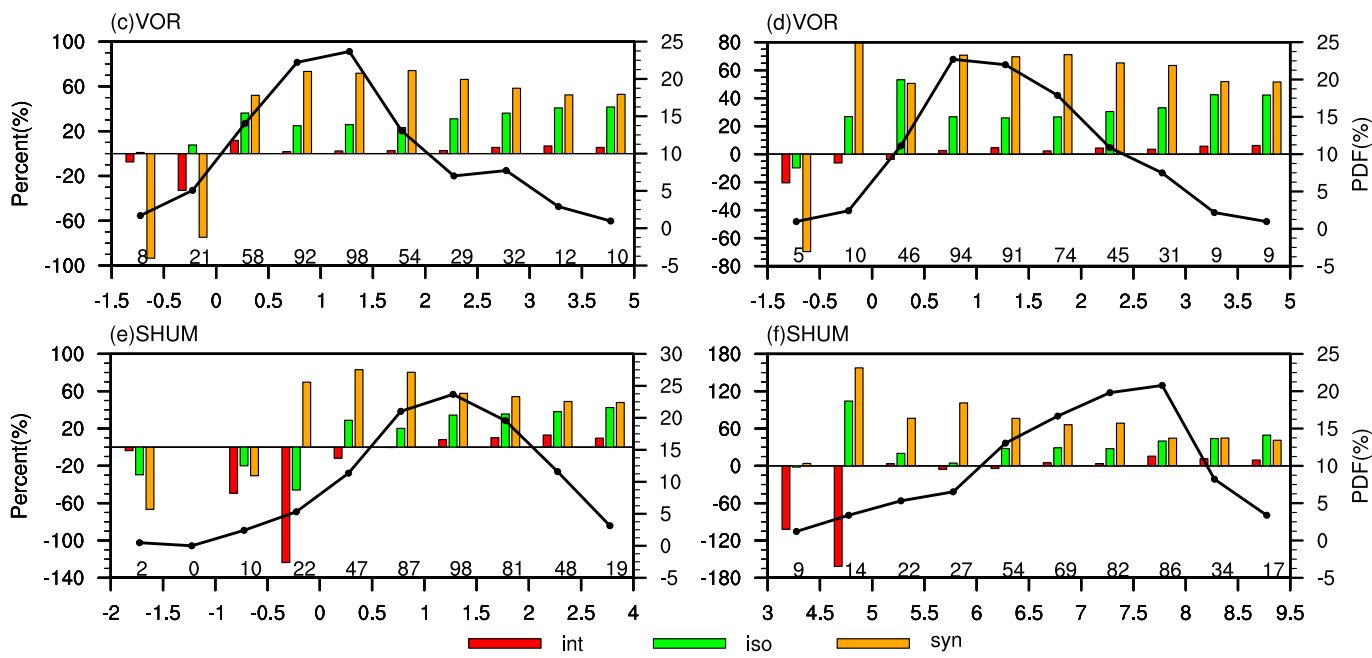

FIG. 2. (left) Relative (\%) distribution of anomalies of (a) OLR, (c) 850-hPa relative vorticity, and (e) 700-hPa specific humidity on interannual (red bar), intraseasonal (green bar), and synoptic (orange bar) time scales associated with the 414 TCs over the NTA during JASO of 1979-2013. The $x$ axes in (a), (c), and (e) are the anomalies of OLR $\left(\mathrm{W} \mathrm{m}^{-2}\right)$, relative vorticity $\left(10^{-5} \mathrm{~s}^{-1}\right)$, and specific humidity $\left(\mathrm{g} \mathrm{kg}^{-1}\right)$, respectively. (right) As at left, but the climatological mean value is included. (b),(d),(f) The $x$ axes are the total value of OLR $\left(\mathrm{W} \mathrm{m}{ }^{-2}\right)$, relative vorticity $\left(10^{-5} \mathrm{~s}^{-1}\right)$, and specific humidity $\left(\mathrm{g} \mathrm{kg}^{-1}\right)$, respectively. The solid line (scale at right) indicates the PDF of TC genesis number. The value above the $x$ axis indicates the corresponding number of TCs in the respective range.

calculated based on total OLR value, most TCs $(70 \%$, 288/414) form within the OLR range between 190 and $250 \mathrm{~W} \mathrm{~m}^{-2}$ (Fig. 2b). Similarly, the synoptic variation has a major positive contribution and the intraseasonal variation is secondary. When the total OLR value is below $190 \mathrm{~W} \mathrm{~m}^{-2}$, the synoptic and intraseasonal variations have comparable positive contribution (Fig. 2b). When the total OLR value is above $250 \mathrm{~W} \mathrm{~m}^{-2}$, the contributions from the synoptic and intraseasonal variations are negative.

About $73 \%$ of TCs (302/414) occur when the relative vorticity anomalies are between 0 and $2 \times 10^{-5} \mathrm{~s}^{-1}$ (Fig. 2c). Within this range, the major positive contribution is from the synoptic variation, followed by the intraseasonal variation. The interannual variation has a small contribution. With the increase of total vorticity anomalies, the contribution from the intraseasonal variation becomes larger (Fig. 2c). There are 29 TC cases (about $7 \%$ of total) when the vorticity anomalies are negative and the negative contributions are mainly from the synoptic variation (Fig. 2c). When the distribution is calculated based on total vorticity, the main results remain unchanged (Fig. 2d).

About $76 \%$ of TCs (313/414) occur when the midlevel specific humidity anomalies are between 0 and $2 \mathrm{~g} \mathrm{~kg}^{-1}$ with the major positive contributions from the synoptic and intraseasonal variations (Fig. 2e). In comparison, the contribution from the synoptic variation is larger than that from the intraseasonal variation. The contribution of the interannual variation is small. When the total specific humidity anomalies are larger than $2 \mathrm{~g} \mathrm{~kg}^{-1}$, the contribution from the intraseasonal variation is comparable to that from the synoptic variation. There are 34 TC cases (about $8 \%$ of total) forming within negative humidity anomalies (Fig. 2e). The intraseasonal and interannual variations make the major negative contributions to TC genesis when the total specific humidity anomalies are between 0 and $-1 \mathrm{~g} \mathrm{~kg}^{-1}$. When the distribution is calculated based on total specific humidity, most TCs $(70 \%)$ form when the total specific humidity value is between 6 and $8 \mathrm{~g} \mathrm{~kg}^{-1}$ (Fig. 2f). On average, the contribution from 
the synoptic variation is larger than that from the intraseasonal variation in this range. When the total specific humidity value is below $6 \mathrm{~g} \mathrm{~kg}^{-1}$, the interannual variation has a negative contribution to TC genesis, which is opposite to the intraseasonal and synoptic variations (Fig. 2f).

\section{b. Vertical wind shear, SST, and barotropic energy conversion}

Climatological vertical wind shear is westerly shear less than $5 \mathrm{~m} \mathrm{~s}^{-1}$ over the NTA. Thus, weak easterly shear anomalies are expected to be favorable for TC genesis over the NTA. Figure 3a shows the percentage distribution of anomalies of vertical shear of zonal wind between 200 and $850 \mathrm{hPa}$ on three time scales. About $38 \%$ of TCs form when the vertical wind shear anomalies are between -5 and $0 \mathrm{~ms}^{-1}$. Among the three components, the intraseasonal variation makes the largest positive contribution. When vertical wind shear anomalies are positive, the interannual variation is the least unfavorable component as indicated by the smallest value. TC genesis is directly associated with total vertical wind shear. Thus, we show in Fig. $3 b$ the distribution of anomalies of three components calculated based on total vertical wind shear. About $50 \%$ of TCs form in the range of westerly wind shear between 0 and $10 \mathrm{~m} \mathrm{~s}^{-1}$. The main positive contribution is from the interannual and synoptic variations as easterly interannual and synoptic wind shear anomalies are against climatological westerly wind shear. Intraseasonal wind shear anomalies are unfavorable for the TC formation when the total shear is in the range of $5-10 \mathrm{~m} \mathrm{~s}^{-1}$. When the total vertical wind shear is larger than $10 \mathrm{~m} \mathrm{~s}^{-1}$, the interannual and synoptic variations have the least unfavorable contribution because of the relatively small value (Fig. 3b). When the vertical wind shear is below zero, the least unfavorable contribution is from the synoptic variation on average. Those results indicate that the relative contributions of the three time-scale variations of vertical wind shear depend on the magnitude of total vertical wind shear.

The relative contribution of the three components of SST anomalies is distinct from the variables discussed above. Figure 4 a shows the percentage distribution of anomalies of SST on three time scales. About $48 \%$ of TCs form when the SST anomalies are positive, in which the interannual variation has the largest positive contribution to TC genesis. The contributions from the intraseasonal and synoptic variations are small. About half of TCs appear within negative SST anomalies and all the three components make negative contributions to TC genesis (Fig. 4a). This result is consistent with that over the WNP (Cao et al. 2018).
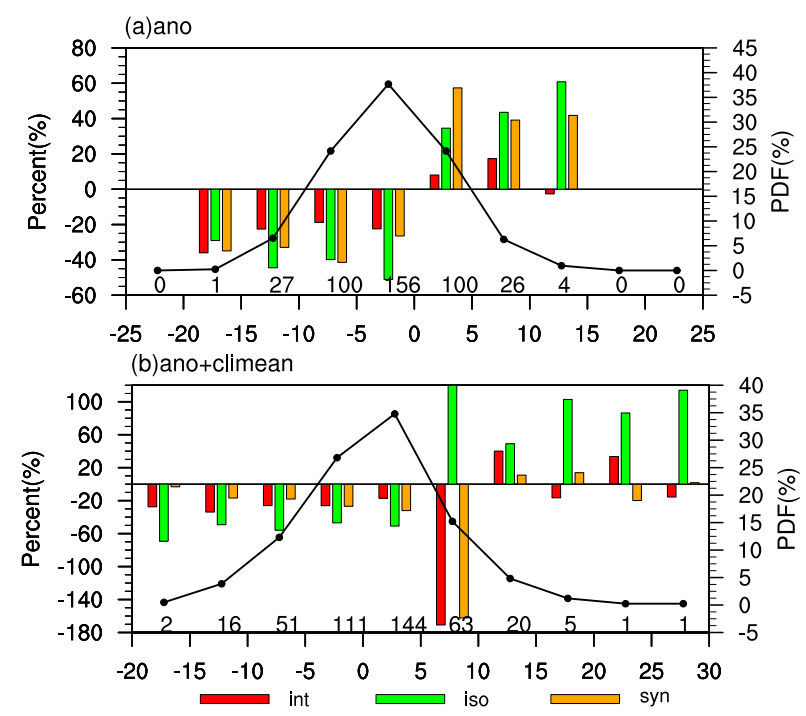

FIG. 3. (a) Relative (\%) distribution of anomalies of vertical zonal wind shear between 200 and $850 \mathrm{hPa}$ on interannual (red bar), intraseasonal (green bar), and synoptic (orange bar) time scales associated with the 414 TCs over the NTA during JASO of 1979-2013. The $x$ axis in (a) is the anomalies of vertical zonal wind shear $\left(\mathrm{m} \mathrm{s}^{-1}\right)$. (b) As in (a), except that the climatological mean vertical zonal wind shear is included. The $x$ axis in (b) is the total value of vertical zonal wind shear $\left(\mathrm{m} \mathrm{s}^{-1}\right)$. The solid line (scale at right) indicates the PDF distribution of TC genesis number. The value above the $x$ axis indicates the corresponding number of TCs in the respective range.

Figure $4 \mathrm{~b}$ shows that about $95 \%$ of TCs form when total SST is above $26.5^{\circ} \mathrm{C}$, which is considered as a necessary condition for TC genesis (Gray 1968, 1979). About $55 \%$ of TCs appear when the SST value is between $27.5^{\circ}$ and $29^{\circ} \mathrm{C}$ (Fig. 4b). In this range, the positive contribution from the interannual variation is overwhelmed by negative contributions from the synoptic and intraseasonal variations. When the SST value is larger than $29^{\circ} \mathrm{C}$, the interannual variation has the largest positive contribution (Fig. 4b). When the SST value is smaller than $27.5^{\circ} \mathrm{C}$, the three component anomalies are all negative with the largest negative contribution from the intraseasonal SST anomalies.

The synoptic-scale disturbances obtain energy from the large-scale basic flows through the barotropic eddy kinetic conversion. TCs over the NTA are generated most frequently when the barotropic energy conversion anomalies are between 0 and $3 \times 10^{-5} \mathrm{~m}^{2} \mathrm{~s}^{-3}$ (Fig. 5). The contribution is mainly related to climatological mean flows and intraseasonal wind variations. The interannual wind variation has a small contribution to the barotropic energy conversion. About 39\% of TCs form when the barotropic eddy conversion anomalies are negative (Fig. 5). It indicates that other types of energy conversions play a role in the development of synoptic 


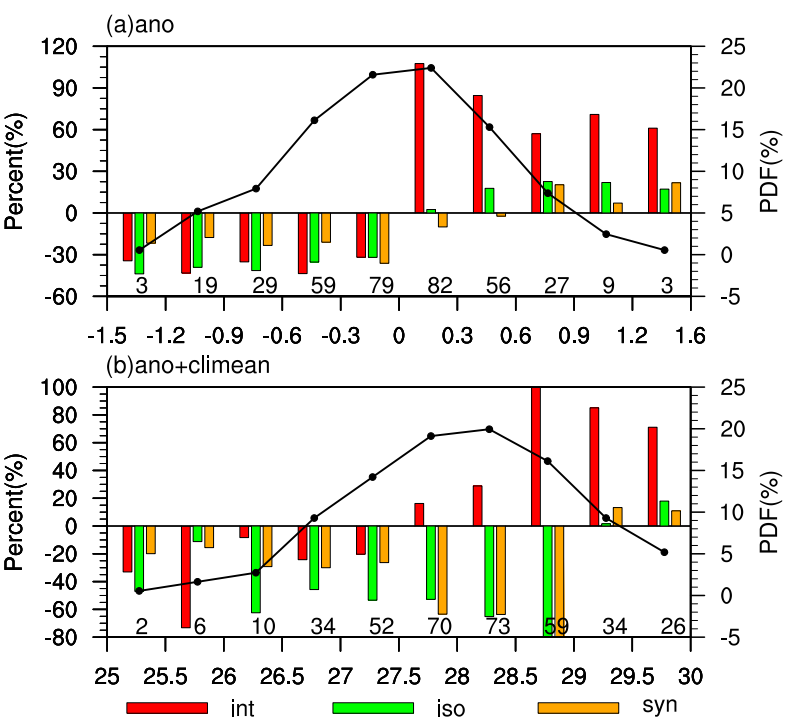

FIG. 4. As in Fig. 3, but for SST associated with the 366 TCs during JASO of 1982-2013. (a),(b) The $x$ axes are the anomalies and total value of $\operatorname{SST}\left({ }^{\circ} \mathrm{C}\right)$, respectively.

disturbances. For example, synoptic disturbances can be generated from convection within the intertropical convergence zone (Hsieh and Cook 2005) and latent heating upstream of the AEW development (Diaz and Aiyyer 2013).

\section{c. The influence of TC signals}

Our approach of composite is based on the location of TC genesis. As such, the TC circulation may contaminate the composite fields. To examine the effect of TC circulation, we remove the cyclonic circulation related to TCs before obtaining the three components of variations of background wind fields. The removal of TC-related cyclonic circulation is based on the algorithm proposed by Kurihara et al. (1995) using the procedure of Bi et al. (2015). First, the total wind is decomposed into a basic flow component and a disturbance component using a smoothing operator. The outer boundary of TC domain is defined at each of $5^{\circ}$-angle bands (along 72 radial directions). The criterion of the outer boundary of TC domain is as follows: 1) the tangential wind speed of the disturbance is less than $3 \mathrm{~ms}^{-1}$ or 2) the tangential wind speed of the disturbance is less than $6 \mathrm{~m} \mathrm{~s}^{-1}$ and its radial gradient is less than $4 \times 10^{-6} \mathrm{~s}^{-1}$. The non-TC flow component within the TC domain is obtained according to an optimal interpolation method using wind data at the outer boundary. Then, this non-TC component is added into the basic flow fields. The major difference between the method used in this paper and that in Bi et al. (2015) is that in their study

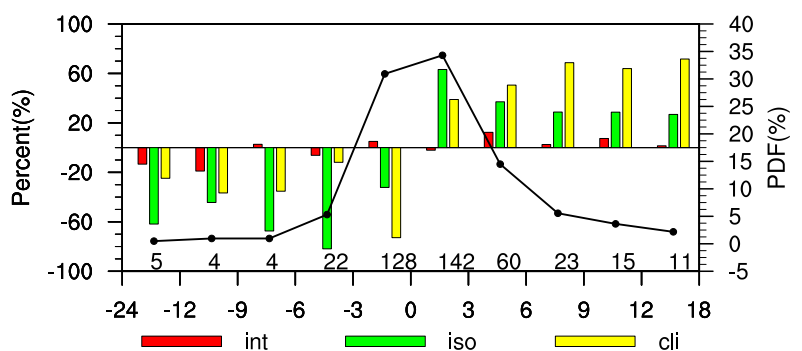

FIG. 5. Relative (\%) distribution of 850-hPa barotropic energy conversion from interannual variation (red bar), intraseasonal variation (green bar), and climatological mean (yellow bar) circulations associated with the 414 TCs over the NTA during JASO of 1979-2013. The $x$ axis is the value of barotropic energy conversion $\left(10^{-5} \mathrm{~m}^{2} \mathrm{~s}^{-3}\right)$. The solid line (scale at right) indicates the PDF of TC genesis numbers. The value above the $x$ axis indicates the corresponding number of TCs in the respective range.

the outer boundary of TC domain is examined along each of 120 radial directions, whereas in the present study it is examined along each of 72 radial directions due to the relatively coarse resolution.

The background fields after the removal of TCs are used to construct the composites of lower-level relative vorticity on the three time scales and compare with those based on total wind fields. For instance, Fig. 6 shows the total wind field, the wind field after TC winds are removed, and their difference (TC winds) at $850 \mathrm{hPa}$ for two cases over the NTA. The first case is 11 August 2005 with one tropical storm (Fig. 6c) and the second case is 25 August 2006 with two tropical storms (Fig. 6f). In the first case, although the TC winds are not obvious in the total wind fields (Fig. 6a), the difference between total winds and TC-removed winds displays a cyclonic vortex around $24^{\circ} \mathrm{N}, 65^{\circ} \mathrm{W}$ (Fig. $6 \mathrm{c}$ ). In the second case, the difference between total winds and TC-removed winds displays two vortices, though incomplete, particularly the one around $22^{\circ} \mathrm{N}, 45^{\circ} \mathrm{W}$ (Fig. 6f).

The TC-related circulation does not appear to change the major results obtained based on total wind field. Figure 7 shows the percentage distribution of relative vorticity at $850 \mathrm{hPa}$ on three time scales using TC-removed winds. About 79\% (325/414) of TCs occur when the lower-level vorticity anomalies are between 0 and $2 \times 10^{-5} \mathrm{~s}^{-1}$. The positive contribution of synoptic variations is larger than that of intraseasonal variations in this range. When the total vorticity anomalies are more than $2 \times 10^{-5} \mathrm{~s}^{-1}$, the synoptic and intraseasonal variations have comparable positive contributions. In addition, 50 TCs (about $12 \%$ of total) form when the total vorticity anomalies are less than zero, in which the largest negative effect 

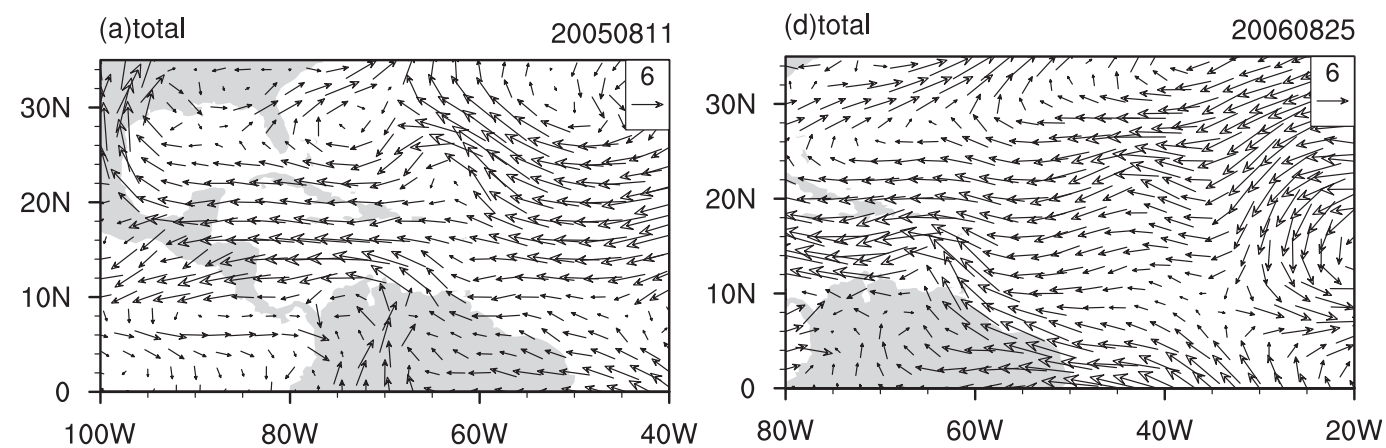

(b)TC-remove

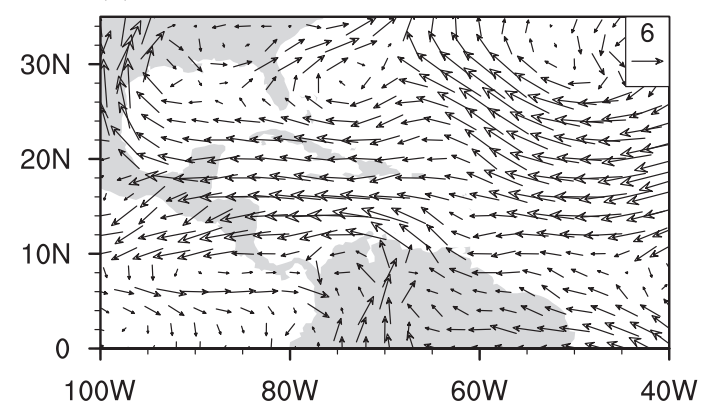

(c) TC

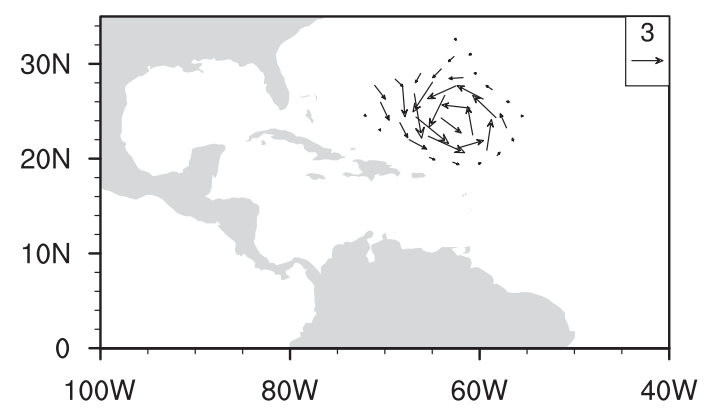

(e)TC-remove

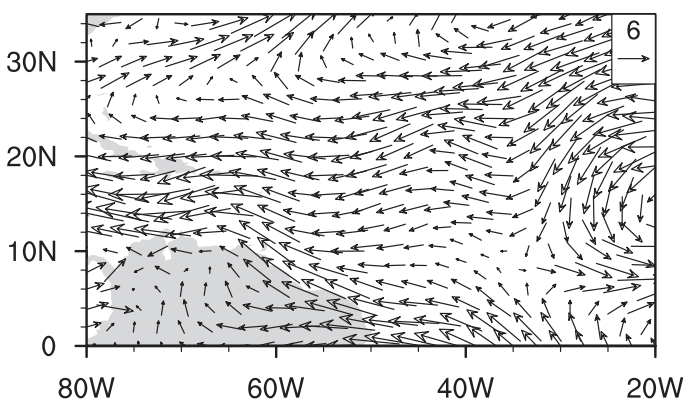

(f) TC

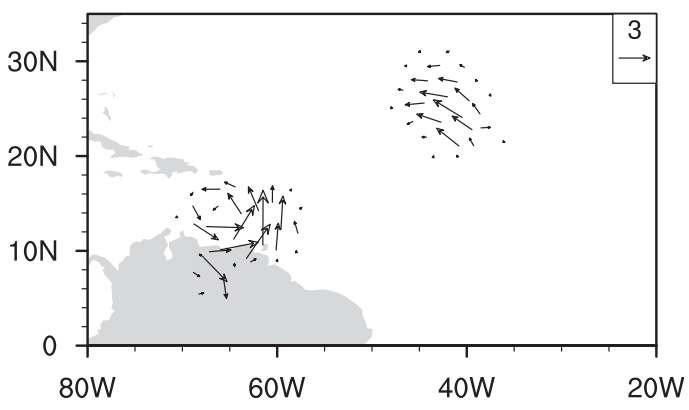

FIG. 6. The 850-hPa wind fields on (left) 11 Aug 2005 and (right) 25 Aug 2006 when TCs existed over the NTA: (a),(d) total and (b),(e) TC removed, and (c),(f) the differences of (a) minus (b) and (d) minus (e), respectively.

is due to the synoptic component. Those results are nearly the same as those in Fig. 2c, which are based on total winds. Note that the vorticity field is likely a variable that is impacted largely by the TC. The TC effect on other variables is expected to be smaller than the relative vorticity due to the different spatial scale.

In this study, TC genesis is defined as the first record when the maximum wind speeds reach $25 \mathrm{kt}\left(12.9 \mathrm{~m} \mathrm{~s}^{-1}\right)$ over the NTA, less than the intensity of tropical storm. Meantime, a large box $\left(7.5^{\circ} \times 7.5^{\circ}\right)$ is used in averaging to represent the environmental impacts on TC genesis. Therefore, it is believed that the results with the total winds reflect the large-scale impacts on TC genesis with little contamination of TC signal. Cao et al. (2018) indicated that the TC signal makes little effect on the major results of the relative contributions of variations on interannual, intraseasonal, and synoptic time scales to TC genesis over the WNP. Thus, in the following section, the original winds are used to compare the difference of relative contributions between different regions.

\section{Comparison between different regions}

The genesis of TCs over the northern tropical Atlantic covers a large zonal extent, over $80^{\circ}$ of longitude (Fig. 1b). Peng et al. (2012) suggested that largescale conditions over the western and eastern Atlantic Ocean are quite different. There are more favorable environmental conditions for TC genesis over the western Atlantic Ocean than over the eastern Atlantic Ocean. A question is whether there are regional 


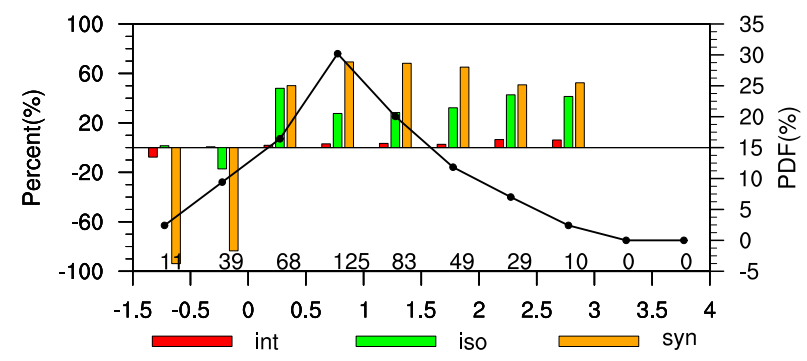

FIG. 7. As in Fig. 2c, but for the 850 -hPa relative vorticity after the removal of TC winds. The $x$ axis is the anomalies of relative vorticity $\left(10^{-5} \mathrm{~s}^{-1}\right)$.

differences in the relative contributions of various factors on the three time scales to TC genesis over the NTA. In this section, we compare the contributions of different time-scale variations to TC genesis between western and eastern NTA. We also compare the differences of contributions of different time-scale variations to TC genesis between the NTA and WNP.

\section{a. Comparison between the western and eastern NTA}

The NTA is divided into western and eastern parts (WNTA and ENTA) separated by the longitude of $55^{\circ} \mathrm{W}$ for a nearly equal area in the two subregions. We note that the meridional extent of TC genesis region is much larger west than east of $55^{\circ} \mathrm{W}$, which is consistent with a larger meridional coverage of high SST in the west than in the east (Fig. 1b). Figure 8 shows the total averaged positive contribution of OLR, relative vorticity, specific humidity, and barotropic energy conversion over the NTA, WNTA, and ENTA. The averaged positive contributions of three timescale variations of large-scale factors to TC genesis are calculated by the sum of the product of individual percentage contribution and the corresponding TC genesis number rate in each range when total anomalies of vorticity, specific humidity, and barotropic energy conversion are positive or total anomalies of OLR are negative.

The relative contributions of synoptic and intraseasonal components show notable differences over the WNTA and ENTA. Over the ENTA, the contributions of synoptic variations of OLR, relative vorticity, and specific humidity are about 2 and 3 times that of the intraseasonal variations (Figs. 8a-c). Over the WNTA, the difference is smaller between contributions of synoptic and intraseasonal variations of OLR, relative vorticity, and specific humidity. Note that for specific humidity, the NCEP-NCAR reanalysis data show that the contribution of synoptic and intraseasonal variations is comparable over the ENTA (figure not shown), which differs from ERA-Interim.
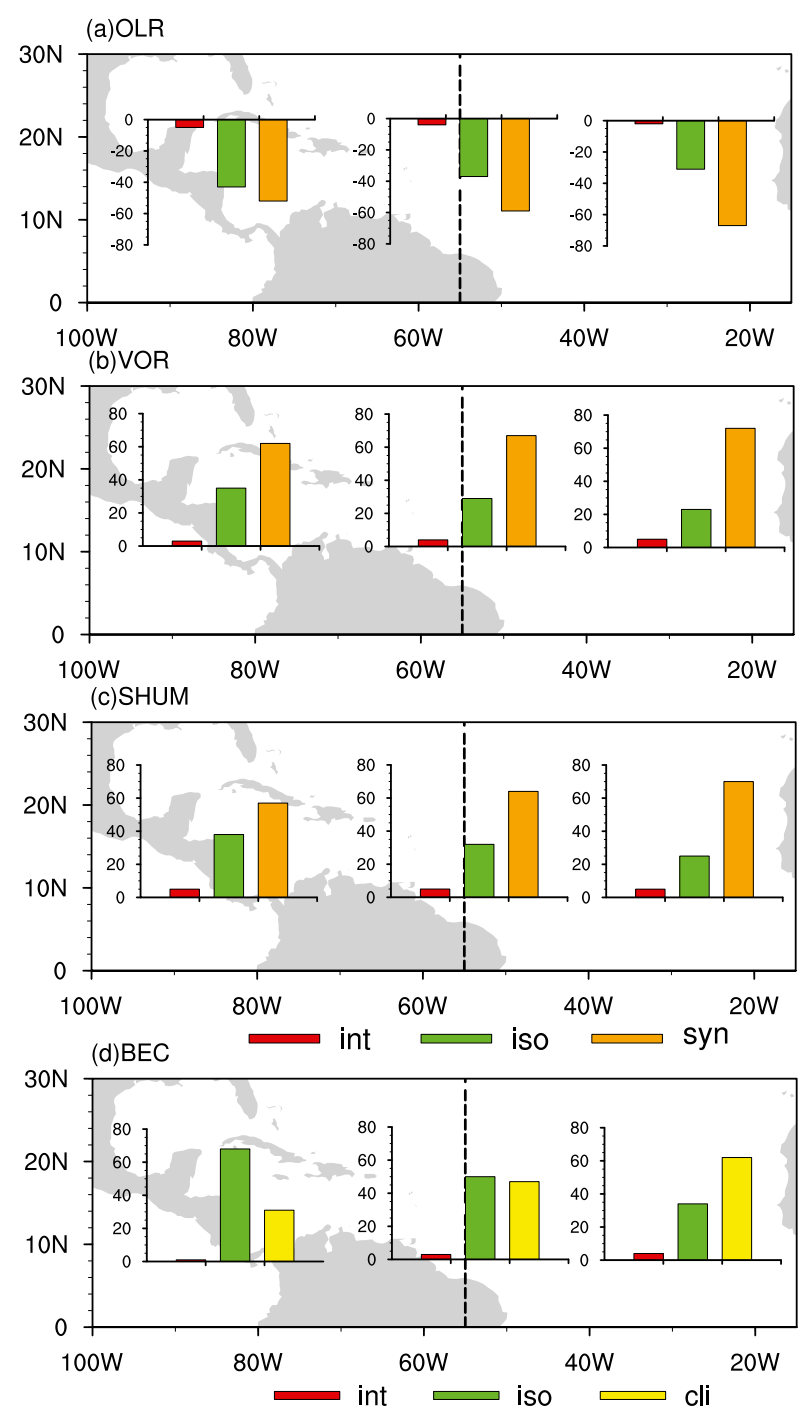

FIG. 8. The contribution ( $\%$ ) of TC genesis with positive contributions from anomalies of (a) OLR, (b) relative vorticity, (c) specific humidity on interannual (red bar), intraseasonal (green bar), and synoptic (orange bar) time scales, and (d) barotropic energy conversion from interannual variation (red bar), intraseasonal variation (green bar), and climatological mean (yellow bar) circulations over (left) the western NTA, (center) the whole NTA, and (right) the eastern NTA.

The above regional differences in contributions of synoptic and intraseasonal variations may be explained by the origin and propagation of synoptic and intraseasonal signals. The synoptic-scale disturbances over the NTA, such as the AEWs, originate from the Sahel during the West African monsoon period and propagate westward over the Atlantic Ocean (Burpee 1972; Reed et al. 1977; Chen et al. 2008). Some of the AEWs may be generated in the intertropical convergence zone (Hsieh and Cook 2005; Diaz and Aiyyer 2013). Thus, the synoptic-scale disturbances are more active over 
the ENTA than over the WNTA. The intraseasonal oscillations, however, propagate from west to east and they tend to weaken during the eastward propagation over the NTA (Maloney and Hartmann 2000). Indeed, the standard deviation of intraseasonal OLR anomalies is larger over the WNTA than over the ENTA and the standard deviation of synoptic OLR anomalies is large along the intertropical convergence zone over the ENTA (figure not shown). To further illustrate the difference of the synoptic and intraseasonal variations, we show in Fig. 9 the ratio of the standard deviation of synoptic and intraseasonal variations. For OLR and specific humidity, the ratio increases eastward over the NTA (Figs. 9a,c). For lower-level vorticity, the ratio is obviously larger east than west of $65^{\circ} \mathrm{W}$ over the NTA (Fig. $9 \mathrm{~b}$ ). Such spatial change agrees with the increase of contribution of the synoptic variations of OLR, relative vorticity, and specific humidity from west to east.

The relative magnitude in the contribution of climatological mean flows and intraseasonal wind variations to the barotropic energy conversion is different over the WNTA and ENTA. The synoptic-scale disturbances obtain a larger part of the barotropic energy from intraseasonal wind variations and climatological mean winds over the WNTA and ENTA, respectively (Fig. 8d). This is related to the difference in the contribution of climatological mean winds and intraseasonal wind variations between the WNTA and ENTA. The contribution of the intraseasonal variations to barotropic energy conversion is about 2 times larger over the WNTA compared to the ENTA (Fig. 8d).

Why do climatological mean flows and intraseasonal wind variations have different effects on the barotropic energy conversion between the WNTA and ENTA? The difference may be explained by the magnitude of meridional shear of zonal wind and zonal convergence of zonal wind, which are involved in the largest two terms in the barotropic energy conversion (Maloney and Hartmann 2001; Wu et al. 2012). We calculate the averaged value of four terms of the barotropic energy conversion in relation to intraseasonal and climatological winds in a $7.5^{\circ} \times 7.5^{\circ}$ box encompassing the TC genesis location in the WNTA and ENTA. Over the WNTA, climatological mean zonal wind increases northward (Fig. 10a), which is unfavorable for the barotropic energy conversion. The climatological easterly wind increases eastward (Fig. 10b) so that there is zonal convergence, which is favorable to the barotropic energy conversion. In contrast, climatological mean zonal wind displays an obvious northward decrease over the ENTA (Fig. 10d), which is favorable for the

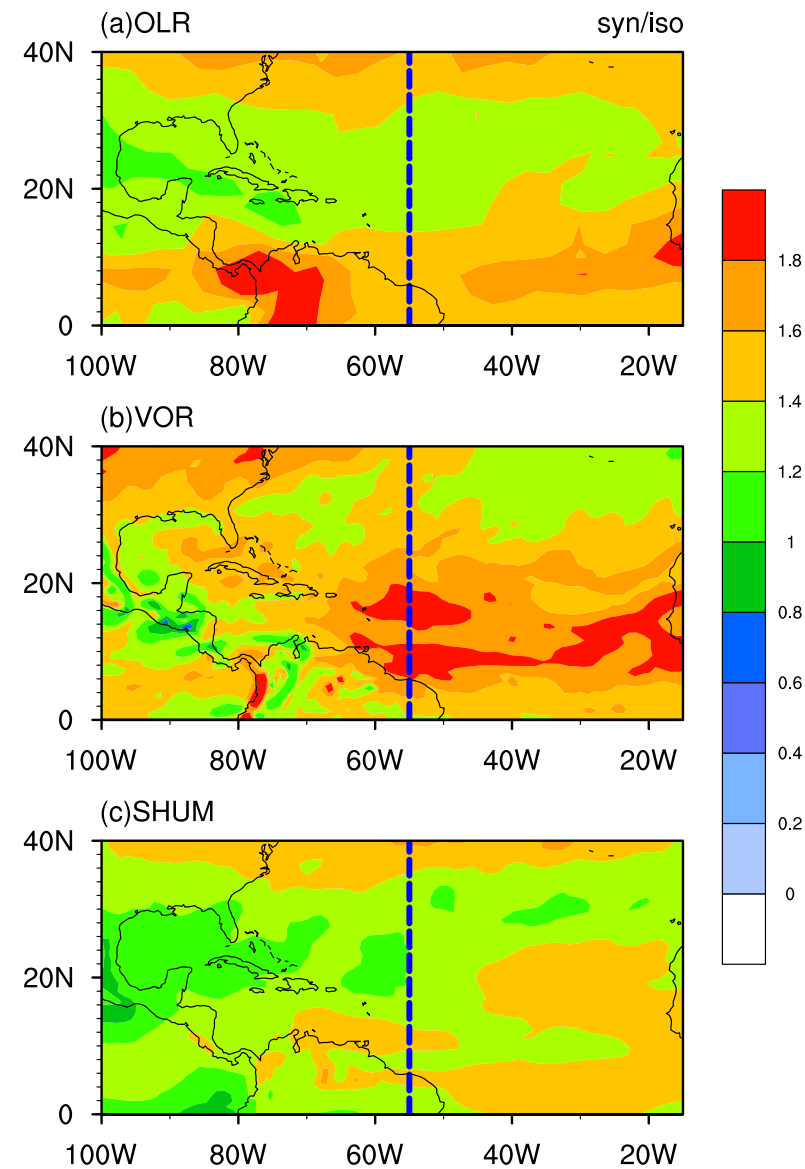

FIG. 9. The ratio of the standard deviations of variations of (a) OLR, (b) low-level relative vorticity, and (c) midlevel specific humidity between the synoptic and intraseasonal time scales over the NTA. The blue dashed line denotes the separation between the western and eastern NTA.

barotropic energy conversion. Climatological zonal wind convergence has a negative effect as the easterly decreases eastward (Fig. 10e), but is overcome by the effect of meridional shear. For intraseasonal zonal wind variations, the meridional shear is larger over the WNTA than over the ENTA (Figs. 10a,d). The zonal convergence appears small in both regions (Figs. 10b,e). Thus, it may be inferred that the intraseasonal wind variations are more favorable over the WNTA than over the ENTA in the barotropic energy conversion. Over the WNTA, the averaged four terms of barotropic energy conversion show that the contribution associated with intraseasonal wind variation is larger than that associated with climatological mean flows and the major positive terms are associated with the meridional shear of zonal wind and zonal convergence of zonal wind (Fig. 10c). Over the ENTA, the contribution of climatological mean flows to the barotropic energy conversion is larger than intraseasonal wind 

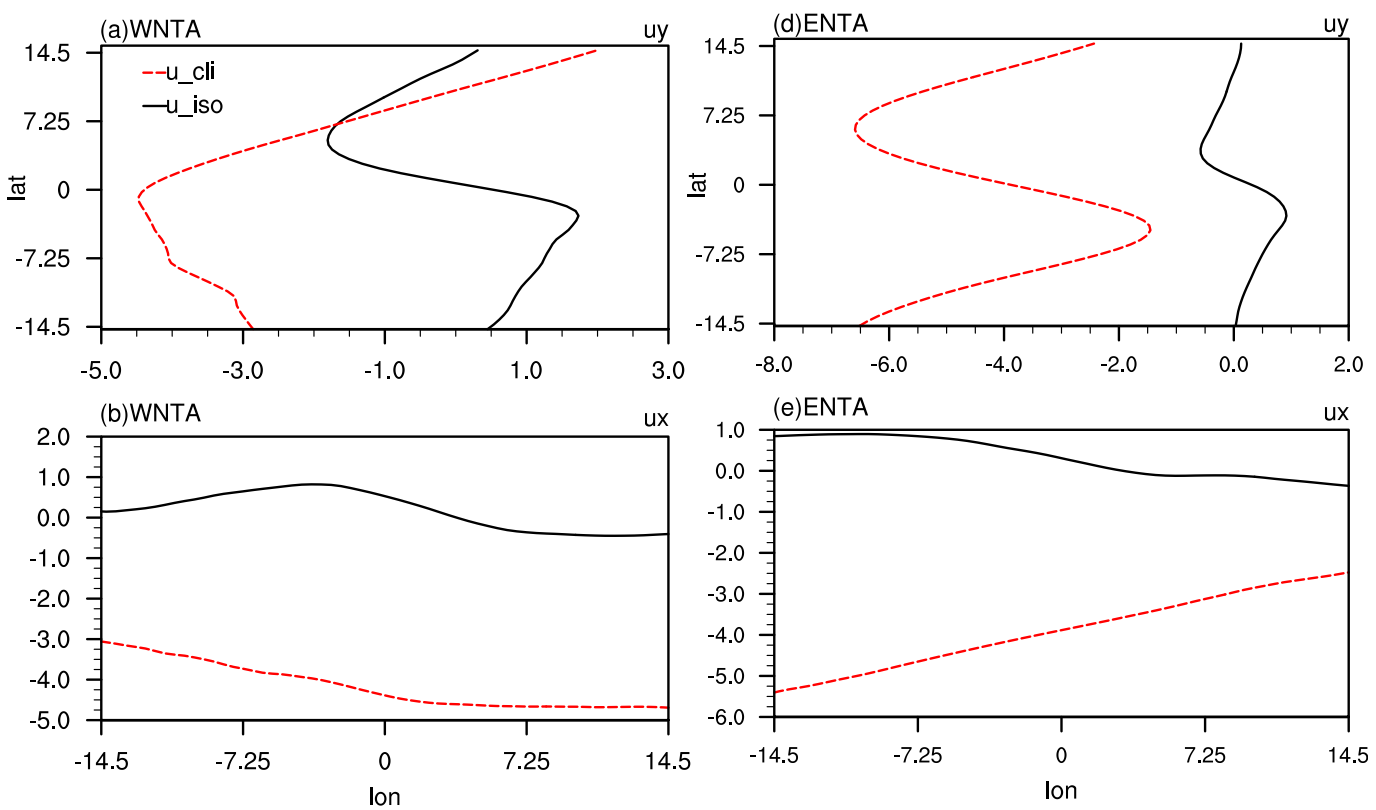

(c)WNTA

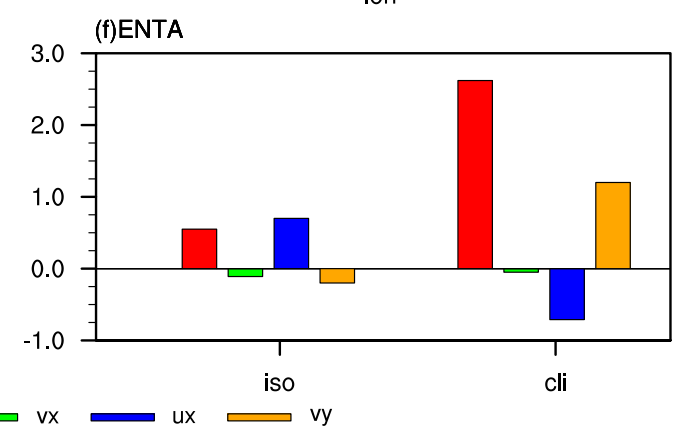

FIG. 10. The composite (a),(d) latitudinal variation of zonal wind, (b),(e) longitudinal variation of zonal wind and (c),(f) four terms of barotropic energy conversion in relation to intraseasonal and climatological winds centered over the location of TC genesis during JASO of 1979-2013 over (left) the WNTA and (right) the ENTA when total anomalies of barotropic energy conversion are positive. The zero on the $y$ axis in (a) and (d) and $x$ axis in (b) and (e) denote the grid point nearest to the location of TC genesis. The $x$ axis in (b) and (e) and the $y$ axis in (a) and (d) represent the distance $\left(^{\circ}\right)$ from the location of TC genesis, with positive distance to the east and north and negative distance to the west and south of TC location.

variations and the major positive terms are associated with the meridional shear of zonal wind and meridional convergence of meridional wind (Fig. 10f).

\section{b. Comparison between NTA and WNP}

Recently, Cao et al. (2018) examined the relative contribution of three time-scale variations of various factors to TC genesis over the WNP. In the following, we investigate differences of relative contributions of environmental factors to TC genesis on various time scales between the NTA and WNP. Note that in the study of Cao et al. (2018), the results are obtained from the NCEP-NCAR reanalysis data. Thus, we recalculated the percentage contribution of three time-scale variations of various factors to TC genesis over the WNP using the high-resolution ERA-Interim dataset.
The major results are consistent. Figure 11 shows the total averaged positive contribution of OLR, relative vorticity, specific humidity, and barotropic energy conversion over the NTA and the WNP.

There are both similarities and remarkable differences in these two regions. Over both the NTA and the WNP, the main positive contributions of OLR (with negative value), vorticity, and specific humidity to TC genesis are from the intraseasonal and synoptic variations. The contributions of the interannual variation are relatively small. Differently, the largest positive contribution of OLR (with negative value) is from the synoptic variation over the NTA, whereas the intraseasonal variation plays a larger role in TC genesis over the WNP (Fig. 11a). With respect to lower-level relative vorticity, the positive contribution 
(a)OLR

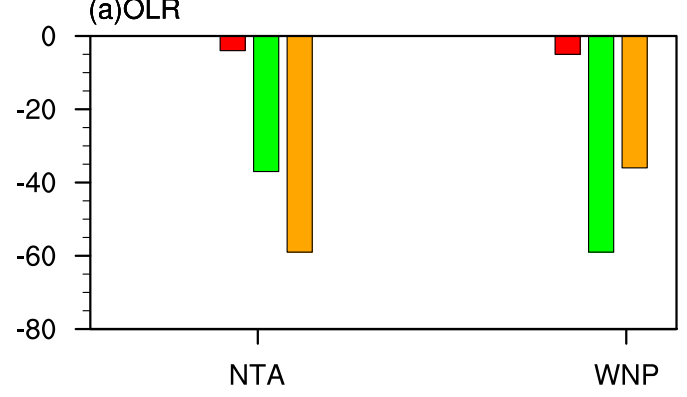

(c)SHUM

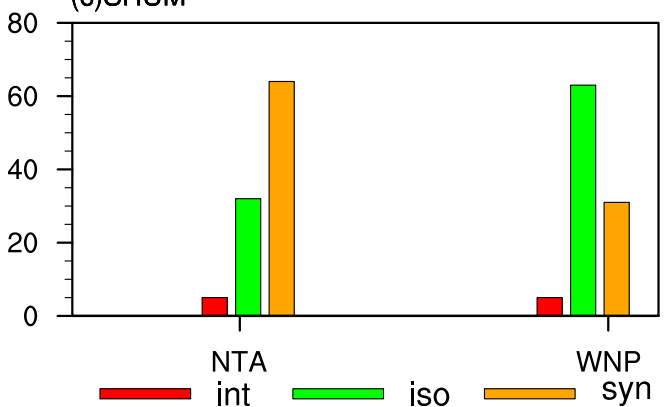

(b) VOR

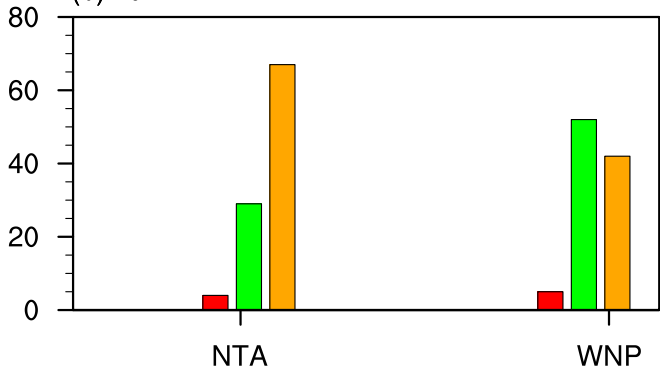

(d)BEC

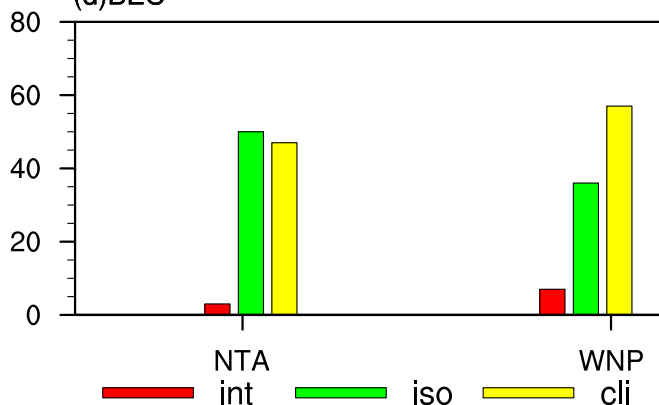

FIG. 11. The percentage (\%) of positive contributions from anomalies of (a) OLR, (b) relative vorticity, (c) specific humidity on interannual (red bar), intraseasonal (green bar), and synoptic (orange bar) time scales, and (d) barotropic energy conversion from interannual variation (red bar), intraseasonal variation (green bar), and climatological mean (yellow bar) circulations over the NTA and the WNP.

from the synoptic variation is 2 times that from the intraseasonal variation over the NTA, while the contributions from the synoptic and intraseasonal variations are close to equal over the WNP (Fig. 11b). For the midlevel specific humidity, the positive contribution from the synoptic variation is nearly 2 times than that from the intraseasonal variation over the NTA, whereas the contribution from the intraseasonal variation is 2 times more than that from the synoptic variation over the WNP (Fig. 11c). The above comparisons indicate that the synoptic variation is the most important component over the NTA, while the leading component is the intraseasonal variation over the WNP.

The difference in the relative contribution of synoptic versus intraseasonal variations to TC genesis appears to be consistent with the ratio of the standard deviations of OLR, relative vorticity, and specific humidity between the synoptic and intraseasonal time scales over the NTA and the WNP. The standard deviations of OLR, relative vorticity, and specific humidity on the synoptic scale are much larger than those on the intraseasonal time scale over the NTA, particularly for the relative vorticity (Figs. 9a-c). Over the WNP, the standard deviations of specific humidity are larger on the intraseasonal time scale than on the synoptic time scale in most of the domain except for the southeastern quadrant (Fig. 12c). The standard deviation of OLR and vorticity is larger on the synoptic time scale than on the intraseasonal time scale, but the ratio is smaller than that over the NTA (Figs. 9a,b and 12a,b). The above comparison appears to explain why the synoptic and intraseasonal variations are the most important components over the NTA and the WNP, respectively.

There are notable differences in the source of barotropic energy conversion between the NTA and WNP. Over the NTA, the synoptic-scale disturbances obtain the barotropic energy nearly equally from climatological mean flows and intraseasonal variation of circulations when the barotropic energy conversion is favorable for TC genesis (Fig. 11d). Over the WNP, the synoptic-scale disturbances mainly obtain the energy from climatological mean flows, about 1.5 times that from the intraseasonal variation of circulations. Cao et al. (2018) surmised that this may be mainly associated with the climatological mean monsoon trough over the WNP. In both regions, the barotropic energy conversion related to the interannual wind variations is small.

The difference in the contribution of climatological mean flows and intraseasonal wind variations to the barotropic energy conversion may be related to the meridional shear of zonal wind and the zonal 
(a)OLR

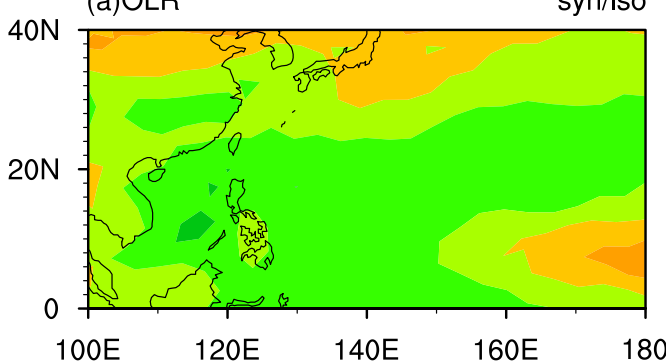

(b) VOR

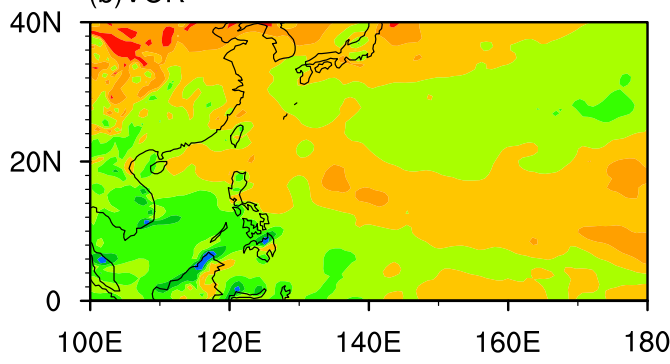

(c)SHUM

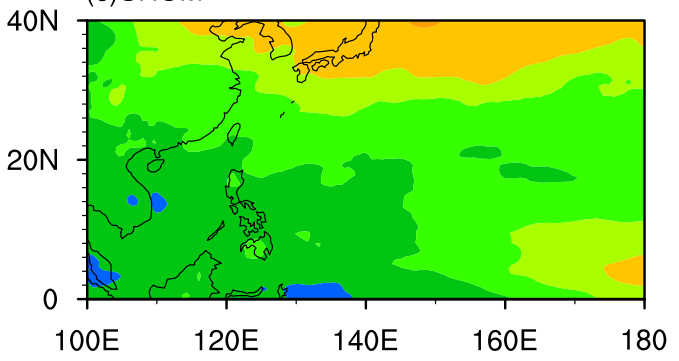

FIG. 12. As in Fig. 9, but over the WNP.

convergence of zonal wind, the two most important terms associated with the barotropic energy conversion (e.g., Cao et al. 2012; Wu et al. 2012). Figure 13 shows the composite zonal wind variations with longitude and latitude centered over the location of TC genesis and the four terms of barotropic energy conversion in relation to climatological mean winds and intraseasonal wind variations during JASO of 1979-2013 over the NTA and the WNP. Over the NTA, the meridional variation of zonal wind is nearly equal on the intraseasonal time scale and on climatological mean (Fig. 13a). The zonal convergence of zonal wind is positive on intraseasonal variations and negative on climatological mean winds (Fig. 13b). Over the WNP, the meridional variation of zonal wind is somewhat larger on the intraseasonal variation than climatological mean (Fig. 13d). However, the zonal convergence of zonal wind associated with the climatological mean is remarkably larger than on the intraseasonal variation (Fig. 13e). Over the NTA, the positive contribution in relation to intraseasonal wind variations associated with the meridional shear of zonal wind and the zonal convergence of zonal wind, as well as that in relation to climatological mean winds, is associated with the meridional shear of zonal wind and the meridional convergence of meridional wind (Fig. 13c). Over the WNP, the positive contributions of intraseasonal wind variations and climatological mean winds are both associated with the meridional shear of zonal wind and the zonal convergence of zonal wind (Fig. 13f). The terms associated with the zonal shear of meridional wind and the meridional convergence of meridional wind on intraseasonal time scale have a large negative contribution (Fig. 13f). This leads to a larger overall contribution of the barotropic energy conversion associated with climatological mean winds over the WNP. Comparing the two regions, apparently climatological mean zonal wind-related meridional shear and zonal convergence have a larger effect on the barotropic energy conversion over the WNP than over the NTA (Figs. 13c,f). In addition, the percentage of TCs forming in the negative barotropic energy conversion is obviously higher over the NTA than over the WNP (39\% vs $26 \%$ ). This indicates that the latent heating and baroclinic energy conversion supply a larger part of the energy source for the development of the synoptic-scale disturbances over the NTA than over the WNP (McTaggart-Cowan et al. 2013).

\section{Summary and discussion}

This study examines the contributions of six environmental factors (convection, lower-level relative vorticity, midlevel moisture, vertical zonal wind shear, SST, and barotropic energy conversion) to TC genesis over the NTA from a local and instantaneous viewpoint. We separate the anomalies centered on the location of TC genesis into interannual, intraseasonal, and synoptic components and analyze and compare their respective contributions. The contributions of the three components to TC genesis are examined for subregions to investigate the regional dependence. The main conclusions and comparisons between different regions are summarized in Table 1.

The results show that the major positive contributions of convection to TC genesis over the NTA are due to synoptic and intraseasonal variations. For the vorticity and specific humidity, the contribution from the synoptic variation is almost 2 times that from the intraseasonal variation. When the convection and vorticity anomalies are unfavorable to TC genesis, the major negative effect of convection is from synoptic variation, while the major negative effects of midlevel specific humidity are from 

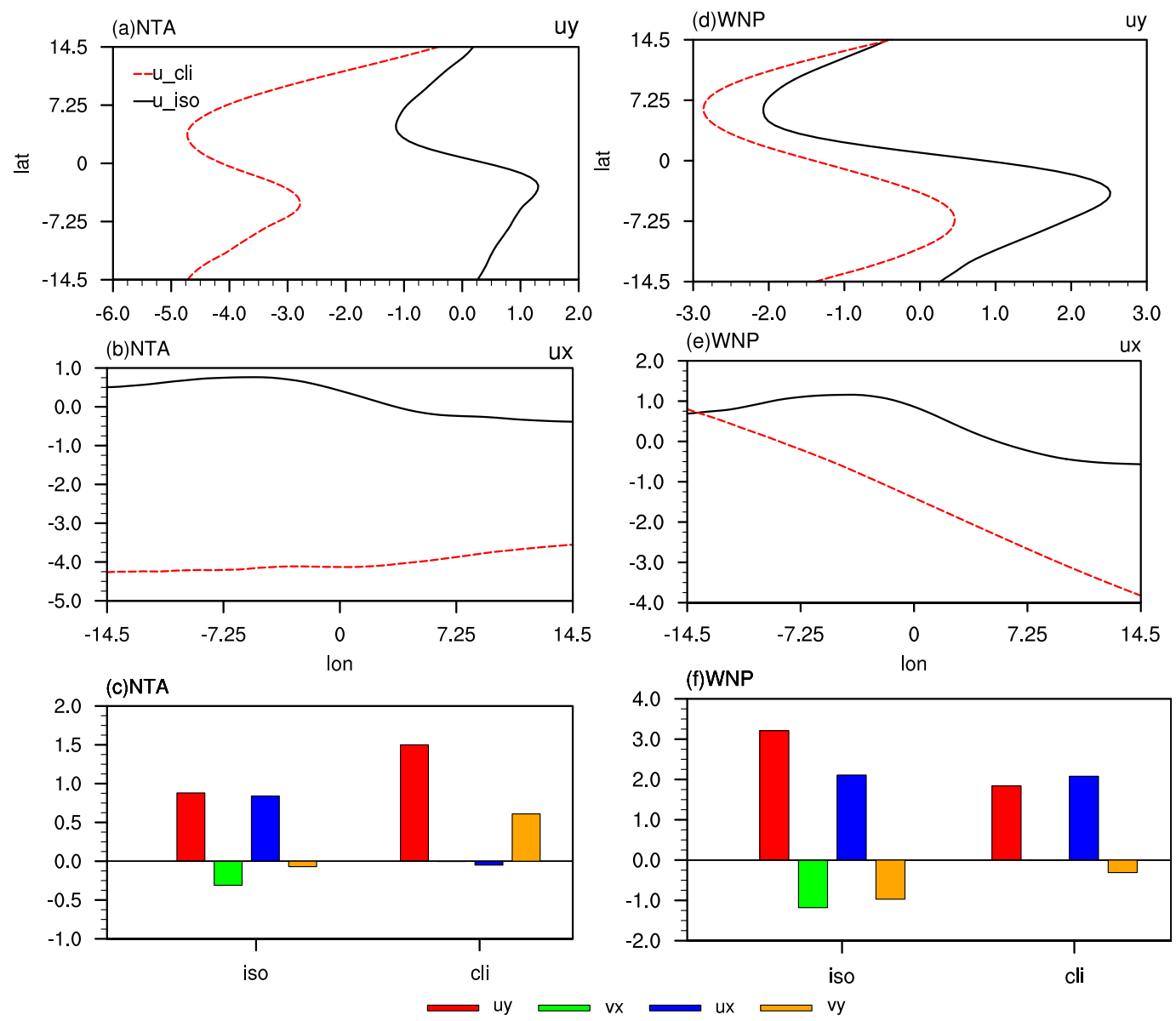

FIG. 13. As in Fig. 10, but over (a)-(c) the NTA and (d)-(f) the WNP.

synoptic and interannual variations. Most TCs form when total vertical zonal wind shear is between 0 and $10 \mathrm{~m} \mathrm{~s}^{-1}$ with comparable positive contributions from synoptic and interannual variations. When total vertical zonal wind shear is larger than $10 \mathrm{~m} \mathrm{~s}^{-1}$, the least unfavorable contribution is from interannual and synoptic variations. The TC genesis over the NTA is largely dependent on climatological mean background SST and interannual variation of SST anomalies. The synoptic-scale disturbances obtain eddy kinetic energy mainly from climatological mean flows and the intraseasonal variation of circulations with a comparable contribution of the two to the development of tropical disturbances.

The relative contributions of large-scale parameters to TC genesis show several regional differences over the NTA. Over the ENTA, the contribution of synoptic variation of OLR is 2 times that of the intraseasonal variation, and the contribution of synoptic variation of relative vorticity and specific humidity is 3 times that of the intraseasonal variation. Over the WNTA, the differences of contributions are smaller between synoptic

TABLE 1. A summary of components of various factors that make the main contributions to TC genesis over the WNTA, ENTA, NTA, and WNP. The main components are determined according to relative magnitude of contributions among the three components to TC genesis. When the contributions from two components to TC genesis are both important, they are listed in order according to their relative magnitudes.

\begin{tabular}{lllll}
\hline \hline & \multicolumn{1}{c}{ OLR } & \multicolumn{1}{c}{ VOR } & \multicolumn{1}{c}{ BEUM } \\
\hline WNTA & Synoptic + intraseasonal & Synoptic & Synoptic + intraseasonal & Intraseasonal \\
ENTA & Synoptic & Synoptic & Synoptic & Climatological mean \\
NTA & Synoptic & Synoptic & Synoptic & Climatological mean + intraseasonal \\
WNP & Intraseasonal & Intraseasonal + synoptic & Intraseasonal & Climatological mean \\
\hline
\end{tabular}


and intraseasonal variations of OLR, relative vorticity, and specific humidity. The synoptic disturbances mainly obtain the barotropic energy from intraseasonal wind variations and climatological mean winds over the WNTA and ENTA, respectively.

The differences between the WNTA and ENTA appear to be related to the origins and propagations of synoptic disturbances and intraseasonal perturbations. Synoptic disturbances are expected to be more active and frequent over the ENTA, which is close to the region of generation of synoptic disturbances. Intraseasonal perturbations tend to propagate eastward and thus may be more energetic over the WNTA. The climatological mean winds have a larger shear and thus have a larger effect on the barotropic energy conversion over the ENTA than over the WNTA.

Comparison between the NTA and the WNP shows that the synoptic variations of OLR, relative vorticity, and specific humidity are the most significant component over the NTA, whereas the leading component of these three factors is the intraseasonal variation over the WNP. Further analysis shows that the standard deviations of OLR, relative vorticity, and specific humidity are much larger on the synoptic scale than on the intraseasonal time scale over the NTA. Over most of the WNP, the standard deviations of OLR and specific humidity are comparable or slightly larger on the intraseasonal time scale than on the synoptic time scale. Over the NTA, the synoptic-scale disturbances obtain the barotropic energy nearly equally from climatological mean flows and intraseasonal variation of winds. In contrast, over the WNP, the synoptic-scale disturbances obtain the barotropic energy mainly from climatological mean flows, which is nearly 1.5 times that from the intraseasonal variation of winds. This is mainly associated with large meridional variation and zonal convergence of climatological mean zonal winds over the WNP.

One issue that may be a concern is the insignificant contribution of the interannual component to the environment of TC genesis. Previous studies have identified the impacts of interannual anomalies of seasonal-mean fields in the year-to-year change in the TC frequency and number. Different from previous studies, the present study is concerned with the anomalies at the instantaneous time and specific location of TC genesis and the relative contributions of the three components to the total anomalies of different variables. Our results show that interannual anomalies have a negligible contribution to the anomalies at the TC genesis in a climatological sense. Are the interannual components important for the year-to-year changes in the anomalies at the TC genesis? Cao et al. (2018) showed that interannual components are important to the difference of anomalies over the WNP region between El Niño developing and decaying years. Our analysis indicates that this is also the case over the NTA region. Figure 14 shows the percentage of TC genesis with positive contributions from anomalies of OLR, relative vorticity, specific humidity, and barotropic energy conversion over the NTA based on 7 El Niño years (1982, 1987, 1991, 1997, 2002, 2004, and 2009) and 7 La Niña years $(1985,1988,1998,1999,2007,2010$, and 2011). There are 65 TCs in the 7 El Niño years and 96 TCs in the 7 La Niña years. The synoptic variations of convection, vorticity, and specific humidity have the largest contribution to TC genesis, followed by the intraseasonal variations, and the interannual variations have the smallest contribution in both the El Niño and La Niña years. The barotropic energy conversion is mainly related to climatological mean flow and intraseasonal wind variations. However, the interannual variations are important in the contribution difference of convection, relative vorticity, and specific humidity between the El Niño and La Niña years. This suggests that the yearto-year change of TC genesis is associated with the interannual variation of large-scale variables.

We note that two datasets are used to investigate the relative contributions of different variables to TC genesis. The results are consistent between the NCEP-NCAR reanalysis and ERA-Interim datasets regarding relative contributions of three components of convection, lower-level vorticity, and specific humidity as well as the differences of contributions of three components of convection and lower-level vorticity between western and eastern NTA. Discrepancies are noted for differences of relative contributions of synoptic and intraseasonal components of specific humidity between the western and eastern NTA between the two datasets. The synoptic (intraseasonal) component of specific humidity has a larger contribution in the eastern (western) NTA based on ERA-Interim, whereas it is opposite based on the NCEP-NCAR reanalysis.

The present study focuses on the contributions of the three components separated based on time filtering. We note that there may be interactions among different variables and even different time scales that cannot be addressed using the present methodology. Camargo et al. (2009) diagnosed the modulation of the MJO to TC genesis using an empirical index and concluded that the nonlinearity between different variables is weak and the effectively linear analysis is valid in their study. Jiang et al. (2012) linearized a genesis potential index (GPI) equation into 4 linear terms plus 11 nonlinear terms. They showed that the nonlinear terms are relatively small over different phases of intraseasonal variability. In the future, we plan to extend the work of Jiang et al. (2012) to discuss the interactions among different terms and different time scales quantitatively.

In this study, we conduct a composite analysis of the relative contributions of three time-scale variations of 

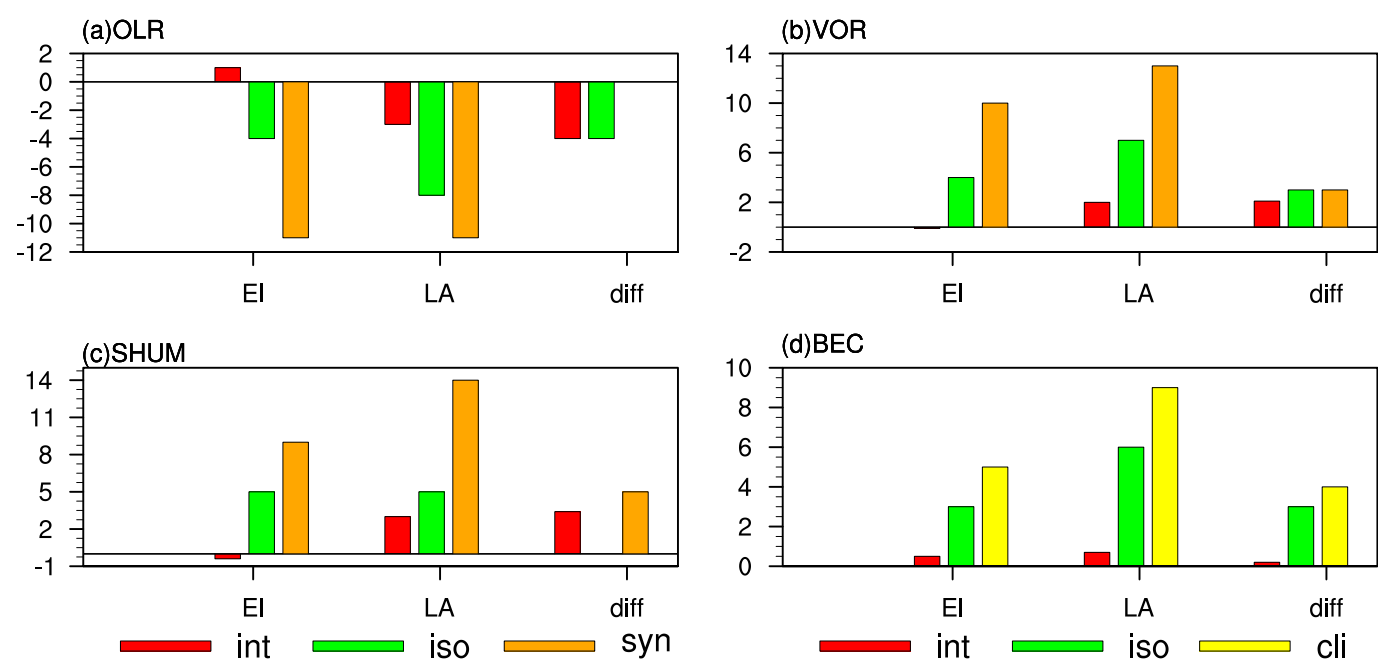

FIG. 14. The percentage of TC genesis with positive contributions from anomalies of (a) OLR, (b) relative vorticity, (c) specific humidity on interannual (red bar), intraseasonal (green bar), and synoptic (orange bar) time scales, and (d) barotropic energy conversion from interannual variation (red bar), intraseasonal variation (green bar), and climatological mean (yellow bar) over the whole NTA during El Niño (El) and La Niña (LA) years. The percentage has been rescaled by multiplying the ratio of the TC numbers in the El Niño and La Niña JASO over the total TC numbers in all the JASO. The difference of percentage of four factors between the El Niño and La Niña JASO (diff) is also shown.

large-scale factors to TC genesis over the NTA. In the future, more effort will be made to investigate the relative contributions of dynamic and thermodynamic variables to TC genesis using a series of idealized numerical simulations. Recently, Cao and Wu (2018) investigated how the large-scale fields, including both interannual variation of the monsoon trough and the climatological mean fields, result in TC genesis over the WNP through numerical simulations. We will perform similar studies to examine the effect of mean states to TC genesis over the NTA.

Acknowledgments. The comments of the editor and three anonymous reviewers have led to improvement of this paper. This study is supported by the National Key R\&D Program of China (2018YFC1507702), the National Key Research and Development Program of China (Grant 2016YFA0600603), the National Natural Science Foundation of China (Grants 41505048, 41475081, and 41775080), and the 2018 Open Research Program of the State Key Laboratory of Severe Weather (Grant 2018LASW-B04). The NCEP-NCAR reanalysis data and NOAA OLR data were obtained via ftp://ftp.cdc.noaa.gov/. The ERA-Interim data set was obtained from ECMWF (https://www.ecmwf.int/en/ research/climate-reanalysis/era-interim). The SST data were obtained from ftp://ftp.cdc.noaa.gov/Datasets/noaa. oisst.v2.highres. The IBTrACS data were obtained from http://www.ncdc.noaa.gov/ibtracs/index.php.

\section{REFERENCES}

Avila, L. A., and R. J. Pasch, 1995: Atlantic tropical systems of 1993. Mon. Wea. Rev., 123, 887-896, https://doi.org/ 10.1175/1520-0493(1995)123<0887:ATSO > 2.0.CO;2.

,-- , and J. G. Jiing, 2000: Atlantic tropical systems of 1996 and 1997: Years of contrasts. Mon. Wea. Rev., 128, 3695-3706, https:// doi.org/10.1175/1520-0493(2000)128<3695:ATSOAY>2.0.CO;2.

Bi, M. Y., T. Li, X. Y. Shen, and M. Peng, 2015: To what extent the presence of real-strength tropical cyclones influences the estimation of atmospheric intraseasonal oscillation intensity? Atmos. Sci. Lett., 16, 438-444, https://doi.org/10.1002/asl.579.

Burpee, R. W., 1972: The origin and structure of easterly waves in the lower troposphere of North Africa. J. Atmos. Sci., 29, 77-90, https:// doi.org/10.1175/1520-0469(1972)029<0077:TOASOE >2.0.CO;2.

Camargo, S. J., K. A. Emanuel, and A. H. Sobel, 2007: Use of a genesis potential index to diagnose ENSO effects on tropical cyclone genesis. J. Climate, 20, 4819-4834, https:// doi.org/10.1175/JCLI4282.1.

— - M. C. Wheeler, and A. H. Sobel, 2009: Diagnosis of the MJO modulation of tropical cyclogenesis using an empirical index. J. Atmos. Sci., 66, 3061-3074, https://doi.org/10.1175/ 2009JAS3101.1.

Cao, X., and R. G. Wu, 2018: Simulations of development of tropical disturbances associated with the monsoon trough over the western North Pacific. Atmos. Sci. Lett., 19, e801, https:// doi.org/10.1002/asl.801.

— , P. Huang, G.-H. Chen, and W. Chen, 2012: Modulation of the western North Pacific tropical cyclone genesis by the intraseasonal oscillation of the ITCZ: A statistical analysis. $A d v$. Atmos. Sci., 29, 744-754, https://doi.org/10.1007/s00376-0121121-0.

__ R. Ru, and S.-F. Chen, 2017: Contrast of 10-20-day and 30-60-day intraseasonal SST propagation during summer and winter over the South China Sea and western North 
Pacific. Climate Dyn., 48, 1233-1248, https://doi.org/ 10.1007/s00382-016-3138-z.

— , R. G. Wu, and M. Y. Bi, 2018: Contributions of different time-scale variations to tropical cyclogenesis over the western North Pacific. J. Climate, 31, 3137-3153, https://doi.org/ 10.1175/JCLI-D-17-0519.1.

Chen, T. C., S. Y. Wang, and A. J. Clark, 2008: North Atlantic hurricanes contributed by African easterly waves north and south of the African easterly jet. J. Climate, 21, 6767-6776, https://doi.org/10.1175/2008JCLI2523.1.

Dee, D. P., and Coauthors, 2011: The ERA-Interim reanalysis: Configuration and performance of the data assimilation system. Quart. J. Roy. Meteor. Soc., 137, 553-597, https://doi.org/10.1002/qj.828.

DeMaria, M., 1996: The effect of vertical shear on tropical cyclone intensity change. J. Atmos. Sci., 53, 2076-2087, https://doi.org/ 10.1175/1520-0469(1996)053<2076:TEOVSO > 2.0.CO;2.

Diaz, M., and A. Aiyyer, 2013: The genesis of African easterly waves by upstream development. J. Atmos. Sci., 70, 3492-3512, https://doi.org/10.1175/JAS-D-12-0342.1.

Dunkerton, T. J., M. T. Montgomery, and Z. Wang, 2009: Tropical cyclogenesis in a tropical wave critical layer: Easterly waves. Atmos. Chem. Phys., 9, 5587-5646, https://doi.org/10.5194/acp-9-5587-2009.

Elsner, J. B., 2003: Tracking hurricanes. Bull. Amer. Meteor. Soc., 84, 353-356, https://doi.org/10.1175/BAMS-84-3-353.

Goldenberg, S. B., C. W. Landsea, A. M. Mestas-Nuñez, and W. M. Gray, 2001: The recent increase in Atlantic hurricane activity: Causes and implications. Science, 293, 474-479, https://doi.org/ 10.1126/science. 1060040.

Gray, W. M., 1968: Global view of the origin of tropical disturbances and storms. Mon. Wea. Rev., 96, 669-700, https://doi.org/ 10.1175/1520-0493(1968)096<0669:GVOTOO>2.0.CO;2.

_ 1979: Hurricanes: Their formation, structure and likely role in the tropical circulation. Meteorology over the Tropical Oceans, D. B. Shaw, Ed., Royal Meteorology Society, 155-218.

_ 1984: Atlantic seasonal hurricane frequency. Part I: El Niño and $30 \mathrm{mb}$ quasi-biennial oscillation influences. Mon. Wea. Rev., 112, 1649-1668, https://doi.org/10.1175/1520-0493(1984) $112<1649$ :ASHFPI $>2.0$. CO 2 .

Hsieh, J. S., and K. H. Cook, 2005: Generation of African easterly wave disturbances: Relationship to the African easterly jet. Mon. Wea. Rev., 133, 1311-1327, https://doi.org/10.1175/MWR2916.1.

Jiang, X., M. Zhao, and D. E. Waliser, 2012: Modulation of tropical cyclone activity by the tropical intraseasonal oscillation over the eastern Pacific in a high-resolution GCM. J. Climate, 25, 6524-6538, https://doi.org/10.1175/JCLI-D-11-00531.1.

Kalnay, E., and Coauthors, 1996: The NCEP/NCAR 40-Year Reanalysis Project. Bull. Amer. Meteor. Soc., 77, 437-471, https:// doi.org/10.1175/1520-0477(1996)077<0437:TNYRP>2.0.CO;2.

Klotzbach, P. J., 2010: On the Madden-Julian oscillation-Atlantic hurricane relationship. J. Climate, 23, 282-293, https://doi.org/ 10.1175/2009JCLI2978.1.

Knapp, K. R., M. C. Kruk, D. H. Levinson, H. J. Diamond, and C. J. Neumann, 2010: The International Best Track Archive for Climate Stewardship (IBTrACS): Unifying tropical cyclone data. Bull. Amer. Meteor. Soc., 91, 363-376, https://doi.org/ 10.1175/2009BAMS2755.1.

Kurihara, Y., M. A. Bender, R. E. Tuleya, and R. J. Ross, 1995: Improvements in the GFDL hurricane prediction system. Mon. Wea. Rev., 123, 2791-2801, https://doi.org/10.1175/ 1520-0493(1995)123<2791:IITGHP > 2.0.CO;2.

Landsea, C. W., 1993: A climatology of intense (or major) Atlantic hurricanes. Mon. Wea. Rev., 121, 1703-1713, https://doi.org/ 10.1175/1520-0493(1993)121<1703:ACOIMA > 2.0.CO;2.
Lau, K.-H., and N.-C. Lau, 1992: The energetics and propagation dynamics of tropical summertime synoptic-scale disturbances. Mon. Wea. Rev., 120, 2523-2539, https://doi.org/ 10.1175/1520-0493(1992)120<2523:TEAPDO > 2.0.CO;2.

Liebmann, B., and C. A. Smith, 1996: Description of a complete, interpolated outgoing longwave radiation dataset. Bull. Amer. Meteor. Soc., 77, 1275-1277.

Maloney, E. D., and D. L. Hartmann, 2000: Modulation of hurricane activity in the Gulf of Mexico by the Madden-Julian oscillation. Science, 287, 2002-2004, https://doi.org/10.1126/ science.287.5460.2002.

— , and _ 2001: The Madden-Julian oscillation, barotropic dynamics, and North Pacific tropical cyclone formation. Part I: Observations. J. Atmos. Sci., 58, 2545-2558, https://doi.org/ 10.1175/1520-0469(2001)058<2545:TMJOBD>2.0.CO;2.

—- and J. Shaman, 2008: Intraseasonal variability of the West African monsoon and Atlantic ITCZ. J. Climate, 21, 2898-2918, https://doi.org/10.1175/2007JCLI1999.1.

McTaggart-Cowan, R., T. J. Galarneau, L. F. Bosart, R. W. Moore, and O. Martius, 2013: A global climatology of baroclinically influenced tropical cyclogenesis. Mon. Wea. Rev., 141, 1963-1989, https://doi.org/10.1175/MWR-D-12-00186.1.

Patricola, C. M., R. Saravanan, and P. Chang, 2014: The impact of the El Niño-Southern Oscillation and Atlantic meridional mode on seasonal Atlantic tropical cyclone activity. J. Climate, 27, 5311-5328, https://doi.org/10.1175/JCLI-D-13-00687.1.

Peng, M. S., B. Fu, T. Li, and D. E. Stevens, 2012: Developing versus nondeveloping disturbances for tropical cyclone formation. Part I: North Atlantic. Mon. Wea. Rev., 140, 1047-1066, https://doi.org/10.1175/2011MWR3617.1.

Pielke, R. A., Jr., and C. W. Landsea, 1998: Normalized hurricane damages in the United States: 1925-95. Wea. Forecasting, 13, 621-631, https:// doi.org/10.1175/1520-0434(1998)013<0621:NHDITU>2.0.CO;2.

Reed, R. J., D. C. Norquist, and E. E. Recker, 1977: The structure and properties of African wave disturbances as observed during phase III of GATE. Mon. Wea. Rev., 105, 317-333, https://doi.org/ 10.1175/1520-0493(1977)105<0317:TSAPOA > 2.0.CO;2.

Reynolds, R. W., T. M. Smith, C. Y. Liu, D. B. Chelton, K. S. Casey, and M. G. Schlax, 2007: Daily high-resolution-blended analyses for sea surface temperature. J. Climate, 20, 5473-5496, https://doi.org/10.1175/2007JCLI1824.1.

Russell, J. O., A. Aiyyer, J. D. White, and W. Hannah, 2017: Revisiting the connection between African easterly waves and Atlantic tropical cyclogenesis. Geophys. Res. Lett., 44, 587595, https://doi.org/10.1002/2016GL071236.

Shapiro, L. J., 1977: Tropical storm formation from easterly waves: A criterion for development. J. Atmos. Sci., 34, 1007-1022, https:// doi.org/10.1175/1520-0469(1977)034<1007:TSFFEW>2.0.CO;2.

Smirnov, D., and D. J. Vimont, 2011: Variability of the Atlantic meridional mode during the Atlantic hurricane season. J. Climate, 24, 1409-1424, https://doi.org/10.1175/2010JCLI3549.1.

Thorncroft, C., and K. Hodges, 2001: African easterly wave variability and its relationship to Atlantic tropical cyclone activity. J. Climate, 14, 1166-1179, https://doi.org/10.1175/1520-0442(2001) 014<1166:AEWVAI>2.0.CO;2.

Wu, L., Z. Wen, R.-H. Huang, and R. Wu, 2012: Possible linkage between the monsoon trough variability and the tropical cyclone activity over the western North Pacific. Mon. Wea. Rev., 140, 140-150, https://doi.org/10.1175/MWR-D-11-00078.1.

Xie, L., T. Yan, L. J. Pietrafesa, J. M. Morrison, and T. Karl, 2005: Climatology and interannual variability of North Atlantic hurricane tracks. J. Climate, 18, 5370-5381, https://doi.org/ 10.1175/JCLI3560.1. 